\title{
Development of an Active Flow Control Technique for an Airplane High-Lift Configuration
}

\author{
Arvin Shmilovich ${ }^{1}$, Yoram Yadlin ${ }^{2}$, Eric D. Dickey ${ }^{3}$, Peter M. Hartwich ${ }^{4}$ and Abdi Khodadoust ${ }^{5}$ \\ The Boeing Company, Huntington Beach, CA, 92647
}

\begin{abstract}
This study focuses on Active Flow Control methods used in conjunction with airplane high-lift systems. The project is motivated by the simplified high-lift system, which offers enhanced airplane performance compared to conventional high-lift systems. Computational simulations are used to guide the implementation of preferred flow control methods, which require a fluidic supply. It is first demonstrated that flow control applied to a high-lift configuration that consists of simple hinge flaps is capable of attaining the performance of the conventional high-lift counterpart. A set of flow control techniques has been subsequently considered to identify promising candidates, where the central requirement is that the mass flow for actuation has to be within available resources onboard. The flow control methods are based on constant blowing, fluidic oscillators, and traverse actuation. The simulations indicate that the traverse actuation offers a substantial reduction in required mass flow, and it is especially effective when the frequency of actuation is consistent with the characteristic time scale of the flow.
\end{abstract}

\section{Nomenclature}

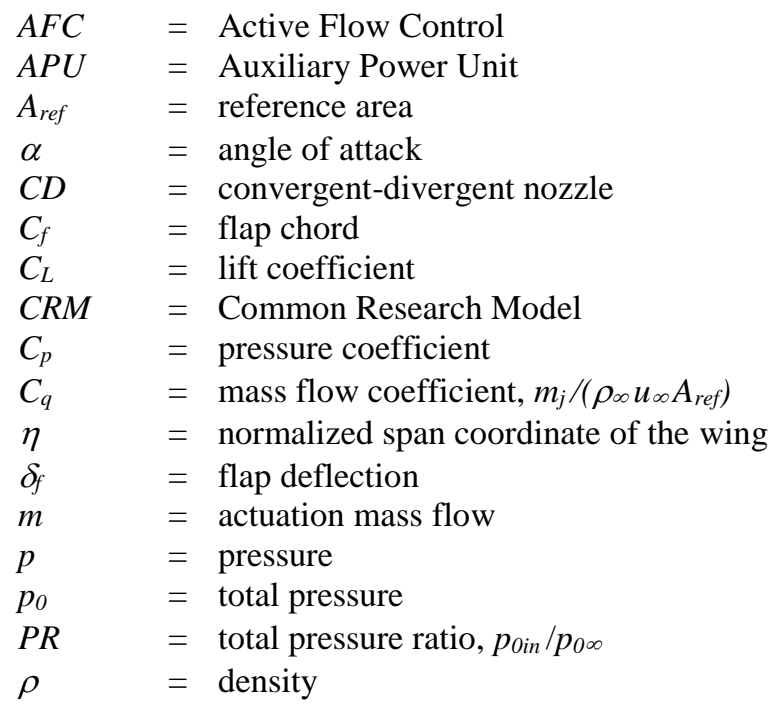

${ }^{1}$ Technical Fellow, Boeing Research and Technology, 14900 Bolsa Chica Rd, H017-D335, Huntington Beach, CA, 92647, AIAA Senior Member.

2 Senior Engineer/Scientist, Boeing Research and Technology, 14900 Bolsa Chica Rd, H017-D335, Huntington Beach, CA 92647, AIAA Senior Member.

3 Senior Engineer/Scientist, Boeing Research and Technology, 14900 Bolsa Chica Rd, H017-D335, Huntington Beach, CA 92647, AIAA Non-member.

${ }^{4}$ Engineering Skills Manager, Engineering, Test \& Technology, 14900 Bolsa Chica Rd, H017-D335, Huntington Beach, CA 92647, AIAA Associate Fellow.

${ }^{5}$ Senior Manager, Advanced Aerodynamic Design, Boeing Research \& Technology, 14900 Bolsa Chica Rd, H017D335, Huntington Beach, CA 92647, AIAA Associate Fellow. 


$\begin{array}{ll}T & =\text { temperature } \\ T_{0} & =\text { total temperature } \\ T R & =\text { total temperature ratio, } T_{0 i n} / T_{0 \infty} \\ u_{\infty} & =\text { velocity } \\ u_{x} & =\text { streamwise component of the velocity } \\ x, y, z & =\text { coordinates along the longitudinal axis, lateral axis, and normal axis, respectively }\end{array}$

\section{Subscript}

in $\quad=$ inlet of actuator

$j \quad=$ actuation jet

$\infty \quad=$ ambient condition

\section{Introduction}

$\mathrm{C}$ urrent airplanes are equipped with high-lift systems that enable safe operation during takeoff and landing. These systems usually consist of movable wing leading-edge slats and trailing-edge flaps. The mechanical devices associated with the high-lift devices employ complex systems of levers, linkages and gears. According to a study conducted by McLean et al., ${ }^{1}$ significant benefits in airplane performance can be realized by using simplified high-lift systems in the form of simple hinge flaps and slats. The advantages stem from the reduced complexity of the mechanical systems, lower weight, reduced actuation power and lower maintenance costs. Additionally, the removal of the flap track fairings associated with conventional high-lift systems renders a more efficient aerodynamic configuration. Hartwich et al. ${ }^{2}$ estimate that potentially, these benefits translate to approximately $2.25 \%$ net reduction in fuel burn for a twin-engine, long-range airplane. However, the simplified high-lift system has to be supplemented with Active Flow Control (AFC) in order to offset the shortfall in aerodynamic performance.

The findings of these exploratory studies have motivated the current project, which is aimed at the development of AFC methods in conjunction with simplified high-lift systems. It addresses a key objective of the NASA Environmentally Responsible Aviation Project (ERA) in terms of reduction in fuel consumption and lower emissions $^{3,4}$. The prospective use of the AFC technology has become especially relevant after the successful demonstration of a full-scale AFC system in flight under a collaborative project between NASA and the Boeing Company $^{5}$. That application was aimed at enhanced control authority of the vertical tail using flow control to suppress the flow separation on the deflected rudder. Since the primary objective of the current study is the control or outright elimination of the flow separation associated with simplified high-lift systems, the experience developed in the vertical tail project was instrumental in guiding the strategy for the AFC implementation.

This study is an element of the NASA Advanced Air Transport Technology Project whose objective is to identify and demonstrate potential benefits of reducing the cruise drag associated with modern high-lift systems ${ }^{6}$. The paper describes the development of AFC solutions for a simplified high-lift system. Computational Fluid Dynamics (CFD) simulations are used to identify the most promising flow control approaches. First, it is demonstrated that flow control applied to the simplified high-lift is capable of attaining the performance of the conventional counterpart at the nominal landing condition. However, in this initial implementation, the mass flow required for actuation is excessive, rendering it impractical. A set of flow control approaches are subsequently analyzed to identify a more efficient implementation. The preferred solution is based on the traverse actuation technique $^{7}$ that offers a substantial reduction in required mass flow. Most importantly, the mass flow required for actuation falls within available resources onboard.

\section{Configuration Definition}

The primary objective of this study is to explore the potential use of AFC for achieving lighter and mechanically simpler high-lift systems for a transonic commercial transport aircraft. An extensive discussion on the design philosophy of the AFC-enabled high-lift system is provided in a companion paper by Hartwich et $\mathrm{al}^{2}$. First, a representative long-range twin-engine transport airplane was selected and its high-lift performance was established. This configuration was derived from the Common Research Model (CRM) outer mold line originally defined for 
transonic cruise conditions ${ }^{8}$. The configuration was modified to incorporate a high-lift system, which is representative of current production type commercial transport. It consists of leading edge slats and a system of trailing edge flaps with Fowler motion.

The simplified configuration was then obtained from the conventional system by replacing the deployable elements with droop leading edges and simple hinge flaps. The moveable elements are similar in size to the slats and flaps of the conventional high-lift system. Wing-fuselage configurations are used to facilitate quick computational turnaround. The focus of the AFC analysis is on the nominal landing condition. The flow control is generally applied in the aft wing region in order to improve the flow quality around the deflected flap elements. Figure 1 shows the landing configurations with the flaps deflected to $30^{\circ}$. Based on the current convention, the inboard flap is deflected to $30^{\circ}$ and the respective outboard flap segment is positioned accordingly in order to create a continuous flap surface in the span direction. In other words, there is no flow through between the outer edge of the inboard flap and the inboard edge of the outer flap. Wing cross sectional cuts through each of the flap elements are also presented. The relative performance of the two high-lift configurations will be established using computational simulations.

\section{Numerical Procedure}

The computational tool used for flow control is a modified version of the OVERFLOW code originally developed by NASA ${ }^{9}$ and it forms the core process of Boeing's transport aircraft CFD. OVERFLOW is based on the unsteady Reynolds Averaged Navier-Stokes formulation for overset grid systems. The numerical procedure has been modified to simulate flows for a family of flow control techniques ${ }^{7,10-16}$. These include constant blowing, pulsed suction/blowing, swiveling jets (sprinkler), fluidic oscillators and traverse actuation. The simulation tool has been generalized for large systems of actuators. In most flow control applications, the computational domain contains the relevant physical region. It consists of the inner regions of the actuators and the external domain, enabling a complete simulation that captures the interplay amongst the actuator jets and the surrounding flow, irrespective of the actuation input. This coupling approach is adequate for any input pressure, whether the actuator flow is subsonic, choked, or intermittently subsonic/supersonic.

In this study, the second order Roe upwind-differencing scheme is used with the ARC3D diagonalized BeamWarming scalar pentadiagonal scheme on the right hand-side. The SA turbulence model has proven robust in the context of the highly separated flows and is used for the simulation cases presented here. The time stepping scheme is second order as demonstrated in the framework of AFC using a system with multiple actuators ${ }^{15}$. The numerical procedure has been extensively validated for numerous applications of $\mathrm{AFC}^{10,12,14-16}$. The validation studies include the characterization of flow control devices for the range of practical actuation parameters, as well as the performance of airplanes equipped with large systems of actuators.

\section{Design Goal for AFC}

The first set of results is used to evaluate the relative performance between the conventional and the simplified configurations. To the extent possible, the analyses use similar grids for the two configurations in order to ensure minimal differences in discretization errors. The simulations are performed for representative landing conditions of the configurations described in Figure 1. Figure 2a shows the lift curves obtained for a free stream Mach number of 0.2 and a Reynolds number of 3.3 million based on the mean aerodynamic chord. The same reference area is used to define the lift coefficients. Not surprisingly, the simplified configuration exhibits significantly lower lift over the range of angles of attack relative to the conventional system. The objective is to recover the shortfall in lift using flow control.

The AFC implementation will focus on the linear lift range, and specifically on the nominal landing condition. From an operational standpoint, stall speed is a determinant of landing field length. Generally, a slower approach speed will result in a shorter field length, where the landing approach speed can be no slower than 1.23 times the stall speed. This determines the lift coefficient corresponding to landing approach, also referred to as nominal landing condition. Based on the lift curve of the conventional configuration, the nominal condition corresponds to 
$\alpha=8^{\circ}$, for which the lift coefficient is 1.67 . This condition is marked by the dashed lines in Figure 2 . Therefore, the AFC application to the simplified configuration has to provide an increase of at least $27 \%$ in lift at nominal landing (relative to the point marked 'A' in Figure 2a). Figure $2 b$ presents the span load distributions at this condition. The wing planform is also shown for reference (gray lines).

In the analysis of $\mathrm{AFC}$, it is instructive to refer to the corresponding baseline inviscid flow of the simplified configuration. The inviscid lift curve in Figure 2 was obtained from a panel method code. It determines the theoretical upper limit to produce lift in the absence of viscous effects ${ }^{9}$. Heuristically, AFC can be interpreted as the means to mitigate the viscous effects and achieve inviscid-like lift levels. Consequently, the inviscid lift level can be used as a yardstick for AFC efficiency. Throughout the following analysis, the inviscid lift is used to gauge the performance of the AFC.

Figure 3 shows the flow fields obtained at the nominal landing condition. The flow fields include the surface pressure distributions and the flow separation bubbles (in gray surfaces). The separated flow is defined by isosurfaces of $u_{x}<10^{-5}$, where $u_{x}$ denotes the streamwise component of the velocity. The slotted flaps of the conventional system are very effective in turning the flow and essentially keeping it attached up to the trailing edges. The simplified configuration produces flow separation, which is triggered by the adverse pressure gradient close to the hinge lines. This is especially evident on the inboard flap. The effect is less pronounced on the outboard flap due to the higher sweep, although pockets of flow reversal form along its span. The flow separation in the aft portion of the wing results in reduced global circulation, commensurate with the lower lift of the simplified configuration. In order to recover the performance of the conventional system, the AFC application to the simplified configuration has to provide a lift increase of at least $27 \%$ at the nominal landing condition. Clearly, the primary role of AFC is the control of the flow separation in the linear lift range.

\section{Flow Control for High-Lift}

A set of actuation approaches, which require fluidic sources, are considered in this investigation. In the initial phase of AFC implementation, the objective is to achieve lift levels comparable to the conventional configuration. The emphasis in the second phase is placed on more efficient actuation concepts, offering better prospects for future practical implementations.

\section{A. Initial AFC assessment}

The most widely used control systems can be classified into two groups. One class consists of piezo-electric actuators, which generate pulsed suction/blowing flows (synthetic jets). The main advantage of piezo-electric actuators is that they are electrically powered. However, their effectiveness is quite limited. The other group consists of fluidic actuators, which are especially effective, but they require air supply such as bleed air off an engine, an Auxiliary Power Unit (APU) or a special purpose compressor. The higher the AFC performance target (incremental lift), the higher the input fluidic requirement is (mass flow). In view of the requirements established here, fluidic actuation will be considered in the context of the current study. The merits of candidate flow control techniques will be evaluated in terms of lift gain relative to input required for actuation.

The flow control approaches considered here include constant and unsteady modes of actuation. From a numerical simulation stand point, depending on the type of actuation, the accurate representation of integrated flow control devices presents a set of computational challenges;

- Large grid systems for systems with many actuators

- Compressible flow, covering a wide range of flow velocities

- From low free stream velocity to supersonic speeds at the individual AFC ports

- Accurate temporal representation of the flow

- Interaction of low frequency waves associated with the global flow and high frequency excitations from the actuation devices

- External flow and internal flow of individual actuators

- Flow physics associated with thin bounded viscous layers, separated flows, vortical elements, and systems of shocks and expansion waves at the actuators. 
Since the analyses place considerable demands on computational resources, it is necessary to adopt a systematic approach that is practical, with the goal of quickly identifying most effective AFC implementations. The analysis process evolved through a sequence of progressively complex flow control representations, starting off with surface boundary conditions, up to complete systems that include dozens of actuators. Selected results illustrating the design process will be presented next.

\section{Surface boundary conditions}

A set of flow control cases utilizing constant blowing are first considered. This is a quick step that helps guide port placement and orientation of the blowing jets. Surface boundary conditions are applied on the outer mold line of the wing, where the blowing velocity is defined by the mass flow rate and the stagnation pressure and temperature. The actuation is applied on both flap elements on narrow strips of similar width, just downstream of the respective hinge lines. The blowing jets are perpendicular to the respective hinge lines and they create an angle of $25^{\circ}$ relative to the local surface. A set of fine local sub grids are placed in that region for capturing the interaction between the jets and the surrounding flow. Several actuation patterns are considered in Figure 4, which shows the controlled flow fields together with the vectors representing the jet efflux. Jet Mach number is 0.65 in all cases. Insight into the effects of the various actuation cases can be gained by referring to the flow fields in Figure 3 . AFC on the inboard segment is very effective in eliminating the flow separation on the inboard flap (Figure 4a). The addition of flow control outboard further improves the flow (Figure 4b), although some flow separation exists in the narrow region between the flap elements where flow control was not used (see inset). In the third case, flow control is applied on both flap elements, where the width of the blowing strip is reduced by about $40 \%$ (Figure 4c). This case indicates that actuation intensity can be further reduced with no major degradation in AFC effectiveness.

\section{Backward-facing step}

A more realistic computational model adopts the implementation described in Reference 16. It incorporates backward-facing steps, which are carved into the flap elements at the location of the AFC jets as shown in Figure 5. The vertical steps coincide with the exit plane of the actuators. Surfaces boundary conditions can be used to prescribe continuous jets on the vertical faces of the step or in a segmented fashion to mimic discrete actuator orifices. The latter is shown in the figure, depicting the efflux vectors. These results are not included in this article.

\section{Blowing nozzles}

A higher level of realism is accomplished by incorporating an array of actuators in the form of convergentdivergent nozzles (CD). This model consists of 19 ports along the inboard flap and 18 ports on the outboard flap. The geometry of the actuators is identical and having the same size, with throat-area to inlet-area ratio of 0.4 . The actuators are essentially planar, with a slight bent to allow for adequate fit within the outer mold lines. The ports are spaced at equal distances on the respective flap elements. The center lines of the nozzles are perpendicular to the respective backward-facing steps. Figure 6a shows a perspective view of the port layout. The actuator geometry is shown in the close-up top view of Figure $6 \mathrm{~b}$ through the transparent wing surface. The actuation is prescribed at the inlet of the individual nozzles by the total pressure and temperature ratios, $P R=p_{0 i n} / p_{0 \infty}$ and $T R=T_{0 i n} / T_{0 \infty}$. Throughout this study $T R=1$. The computational grid consists of 74 million points. CFD simulations were used to guide the orientation of the nozzles to achieve the desired Coanda effect for energizing the boundary-layer flow over the flaps. An initial nozzle orientation at a steeper angle to the flap surface proved ineffective in reattaching the flow over the trailing edge flap. A subsequent design with a shallower nozzles exit angle proved more effective. The difference in the actuator mounting angles can be seen in the sectional cuts in Figure 6c (note that slight difference in the cuts was necessary to facilitate the comparison along the entire length of the nozzles). An inlet supply of $P R=5.5$ is used at each of the actuators to produce high momentum. This condition results in choked flow and a system of shocks and expansion waves that forms in response to the pressure differential along the diffuser. The flow fields are shown in Figures $6 \mathrm{~d}$ and $6 \mathrm{e}$, illustrating that the shallow angle helps streamline the flow along the flap surfaces. The nozzle plumes, which are represented by iso-surfaces of Mach number of 0.7 , adhere better to the surface. Although the shallow jet efflux results in improved flow, there are still pockets of separation on the outer flap. 


\section{Fluidic Oscillators}

An actuation technique based on Fluidic Oscillators (FO) has also been investigated in the present study. Systems of FOs have proven effective for control of separated flows in wind tunnel environments ${ }^{17,18}$, computational studies $^{16}$ and flight demonstrations ${ }^{5}$. The FO (sometimes referred to as sweeping jet) consists of internal flow passages that generate a feedback mechanism that results in a periodic sweeping jet pattern. The computational model for the array of CD nozzles has been generalized for FOs. The FO first introduced by Vatsa et al. ${ }^{19}$ and applied in the aforementioned investigations is adopted here. The FO system is obtained by replacing each of the CD nozzles in the system described in Figure 6 with a similarly sized FO. The implementation is very similar to the airplane vertical tail application described in Reference 16. Due to geometrical constraints the FO geometry also includes a bent to ensure proper fit within the wing. The layout of the FO system is presented in Figures $7 \mathrm{a}$ and $7 \mathrm{~b}$. The inlet is defined by a circular section, which is perpendicular to the plane of the actuator from underneath (not visible), consistent with the supply duct used in the tail application. The actuator consists of a symmetrical internal loop structure, so that when subjected to high pressure supply it results in an unsteady feedback mechanism. This effectively produces a swiveling jet at the exit station, which scrubs the flap surface and energizes the ambient flow over a wide region. The numerical model uses 144 million grid points. The time-stepping integration is performed until the lift force exhibits a limit-cycle behavior. The instantaneous flow field for $P R=5.5$ is presented in Figure $7 \mathrm{c}$, showing the formation of pockets of flow separation along the flaps.

Although the incremental lift is the main performance metric of AFC, further insight into AFC application can be gained from the distribution of the load along the wing. Figure 8a shows the wing span load distributions due to the various actuation modes. The inboard flap actuation (in Figure 4a) produces localized load augmentation, essentially recovering the load distribution of the conventional system inboard. Moreover, it also increases the load in the adjacent outboard region due to the spanwise flow over the highly swept outboard flap element. Flow control on both flap elements (in Figure 4b) increases the load in the midwing section beyond the level obtained with the conventional configuration. A notable trough forms in the region between the two actuation strips, consistent with the flow fields in Figure 4b. The flow control case with the smaller actuated strip outboard (in Figure 4c) results in a load distribution that more closely resembles that of the conventional configuration. The flow control case using the bank of $37 \mathrm{CD}$ actuators described in Figure 7e produces a load distribution that generally resembles that of the conventional system. It should be noted that since the induced drag depends on the span load distribution, these cases illustrate that AFC can be used for tuning of the span load in order to control induced drag. This is especially important for high-lift conditions since the induced drag is the largest component of airplane drag.

Figure $8 \mathrm{~b}$ shows the lift increments as a function of actuation mass flow coefficient, $C_{q}$. Point 'A' represents the baseline lift of the uncontrolled simplified configuration of $C_{L}=1.309$. Clearly the inboard flap application is insufficient in recovering the target lift level. The combined inboard/outboard applications from Figures $4 \mathrm{~b}$ and $4 \mathrm{c}$ result in higher lift than the conventional system. The discrete application of flow control using the bank of CD nozzles with $\mathrm{PR}=5.5$ helps reduce the mass flow required for actuation, while slightly exceeding the target lift level. The mechanism of unsteady flow excitation of the FO system provides further reduction in mass flow, albeit a modest one. At relatively low pressure input the FO produces a double lopsided profile for the time-averaged velocity, which is advantageous in terms of area coverage. However, at high pressure ratios the average velocity profile attains a maximum value at the center line, which resembles the profile of a steady jet flow. This is the reason for the rather limited benefit of the FOs relative to the CD nozzles. The dependency of the velocity profiles on the input pressure for FOs was also observed in the experiments conducted by Pack and Koklu ${ }^{20}$.

At this point, it is instructive to assess the validity of the predictions developed here. This is facilitated using the study of Reference 16 in which the computational tool has been validated with measured flight test data obtained for the AFC application to the vertical tail of the airplane. That application used a system of FOs to control flow separation on the vertical fin when the rudder is deflected, essentially similar to the simple hinge flap application in this study. The computational predictions of side-force due to AFC and the mass flow to achieve it were well correlated with the measured data. That information has been used to estimate the AFC performance of the current application. Interestingly, after accounting for some of the differences between the two setups (area differences between the tail and the wing, free stream velocity, supply temperature and incremental lift), it has been determined that the projected mass flow from the tail data is consistent with the predicted value in the present wing application. The upshot is that the computed estimates of AFC performance of the simplified high-lift system can be viewed as reasonable predictions of realistic conditions for the nominal landing condition. 
For the flow conditions considered here a mass coefficient of 0.001 corresponds to 32lb/sec. Although the initial implementation of AFC demonstrates that the target lift level is attainable, the mass flow required for actuation is excessive. Considering an APU as a potential supply source, the amount available for actuation is 3.2lb/sec $\left(C_{q}=0.0001\right)$, rendering the AFC methods described above impractical. The objective in the next phase of the study is to develop more efficient AFC approaches with substantially lower input requirements.

\section{B. Low input AFC approaches}

\section{Revised simplified configuration}

A revised layout of the simplified high-lift system will be used to facilitate the development of more effective AFC systems. Since flow control is particularly effective in reducing flow separation, it is desirable to devise a configuration that produces sizeable separation in the uncontrolled mode. This can be accomplished with higher flap deflection, larger flap chord $\left(C_{f}\right)$, or a combination thereof. Relative to the original configuration with $\delta_{\mathrm{f}}=30^{\circ}$, the analysis includes a flap deflection of $50^{\circ}$ and $25 \%$ bigger flap chord, for a total of four flap chord/deflection variants.

Heuristically, AFC can be interpreted as the means to mitigate the viscous effects and achieve inviscid-like flows. Therefore, the inviscid flows can be used to gauge the sensitivity of lift to the flap parameters. The inviscid solutions in Figure 9 are obtained from a panel method code. The results indicate that the flap chord size has a relatively small effect on the wing pressure distribution and lift, and only in conjunction with larger flap deflections. In contrast, increasing the flap deflection from $30^{\circ}$ to $50^{\circ}$ results in noticeably higher suction on the upper wing surface and thereby higher lift. The configuration with the original flap chord length and $50^{\circ}$ deflection is therefore chosen as the revised geometry for the remainder of this study. The viscous lift curve of the revised configuration is also shown in Figure 9, with slightly higher level than the original geometry in the linear lift range. The flow field for the nominal landing condition in Figure 10 shows the formation of a larger separation bubble compared to the original simplified geometry (in Figure $3 b$ ).

\section{Actuator layout}

A set of parameters are used to establish proper actuator placement for the revised geometry with the larger flap deflection. Examination of the flow pattern in Figure 10b, which includes off surface streamlines, indicates that the cross flow is mild on the upper-surface of the fixed element of the wing, particularly inboard. To facilitate quick computational turnaround, the mid cross sections of the respective flap elements are used for a series of twodimensional flow analyses (marked by the dash blue lines in Figure 10b). Surface boundary conditions to simulate blowing jets are applied for flow control as described in Section V-A-1. The computed results indicate that jets ejecting at small angles to the local surface are most effective. Also, jets that are closest to the separation point are most effective for reducing flow separation with least amount of mass flow. Generally, the results are similar for both flap sections.

Sample results are shown in Figure 11 for the inboard flap section. Three locations for the blowing jet are considered; the hinge point at $\mathrm{x} 1$, the point of separation $\mathrm{x} 2$ and a location slightly downstream of the separation point at $\mathrm{x} 3$. The distances between neighboring locations are approximately $1.26 \%$ of the chord length of the nondeflected flap section. The jet angles to the local surface are $10^{\circ}$. The three jets with near sonic velocity are capable of attaching the flow over the entire flap. These are the three uppermost points in the lift curves which are clustered around $C_{L} \sim 3.26$ (dash line). The port at the separation point is most effective and requires the least amount of mass flow.

The findings from the parametric study of the two-dimensional simulations were used to guide the application to the revised simplified configuration. Surface boundary conditions were applied to evaluate AFC layout on the flap elements. The results presented here are for the inboard flap application of flow control in a segmented fashion along the span for maintaining a jet angle of approximately $10^{\circ}$ relative to the local surface. Figure 12 shows the solution for jet intensity that achieves the target $C_{L}$ with a mass flow coefficient of 0.0007 . This constitutes a significant improvement relative to the inboard flap application to the original configuration (refer to the flow field in Figure $4 \mathrm{a}$ and the mass flow in 8 b). It also represents about $35 \%$ reduction in mass flow relative to the discrete

American Institute of Aeronautics and Astronautics 
AFC applications to the original geometry. Moreover, the higher efficiency of the current AFC implementation becomes apparent, where control efficiency is defined as lift increment per mass flow. The higher slope of the $C_{L}$ curve in Figure 12a is indicative of more efficient actuation in controlling the larger separation of the revised configuration.

Additional AFC implementations have been explored in the current study and a set of guidelines was developed with regard to AFC layout. For example, AFC application on both flaps enhances lift augmentation but it does not improve actuation efficiency. Since target lift is attainable with just inboard flap actuation, most of the cases in the remainder of this study will not include flow control on the outboard flap. With regard to jet orientation, the analysis of the lateral jet ejection angles (relative to the streamwise direction) reveals that jet blowing in the direction perpendicular to the hinge line is just slightly more effective.

Another aspect of AFC implementation is the treatment at the edge of the flap in the side of body region. Figure $12 \mathrm{~d}$ shows that a sizeable pocket of flow reversal forms in that region due to the flap edge effect. Means of minimizing it would be highly desirable, potentially leading to a further gain in lift. The first factor addresses the seal between the fuselage and the flap. The deflected flap seals to the body over a certain percentage of its chord. The flap geometry used in the simulations in Figure 12 seals over a large portion. This is shown in Figure 13a in close up views for the flow fields as in Figure 12. Figure 13b presents the flow fields for a flap with a much smaller extent of the seal. The flow fields indicate that the extent of the seal has very little effect on the edge effect and the ensuing separation pattern, with no meaningful difference in lift. The remainder of the study uses the original extended seal (as in Figure 13a).

Several flow control approaches have also been tried to improve the flow at the junction with the fuselage. These are summarized in Figure 14. Figure 14b employs a wider jet at the inboard flap segment extending over 20\% of its span. Figure $14 \mathrm{c}$ introduces a jet that blows laterally towards the fuselage at a $30^{\circ}$ angle from the normal to the hinge line. This jet also extends inboard over $20 \%$ of the flap span. Lastly, in Figure $4 \mathrm{~d}$ the original jet is extended inboard towards the side of body. Relative to the original jet in Figure 14a the wider jet has very little impact on the flow. The jet directed towards the fuselage and the extended jet exhibit reduced separation bubbles with slight improvement in the respective lift levels of about 0.016. In the subsequent AFC implementations the actuation will extend as close as possible to the fuselage.

\section{Blowing nozzles}

Based on the findings from the preceding section the computational model has been extended to an array of convergent/divergent nozzles, similar to the system described in Section V-A-3. Forty identical nozzles are placed on a backward facing step that is closely aligned with the separation line along the inboard flap. The lift plots in Figure 15a represent two actuation patterns. Full actuation at all ports and actuation applied to every other port (20 actuated ports). For the same input pressure the mass flow is proportional to the number of actuated ports. Pairs of points obtained at the same pressure ratios are connected by the small dash lines. The results indicate that the alternate port actuation is more effective than the whole port application with respect to mass flow. However, the 20 port actuation requires higher PR for actuation. This is the case when comparing either mass flow for the same lift level, or lift gain for the same mass flow. The latter scenario is displayed in Figure 15b. The supply of PR=12.8 at 20 ports clears up the flap separation over the entire flap, while the denser actuation with $\mathrm{PR}=6.4$ is only partially effective, showing remnants of separation pockets along the span. The inset shows the flow structure close to the actuators for the alternate port pattern. Jet plumes are represented by Mach iso-surfaces in pink. The outlines of the actuated nozzles are clearly visible through the transparent wing surface. The unactuated nozzles are hardly traceable. The flow consists of a spanwise alternating pattern of attached flow downstream of the actuated ports and slivers of reverse flow in the wakes of the unactuated ports.

The set of $20 \mathrm{CD}$ nozzles achieves the target lift using approximately one half of the mass flow required for the surface blowing jets in Figure 12. Evidently, at higher actuation levels the control of separation is essentially complete and the target lift is reached. According to the lift curves in Figure 15a both flow patterns exhibits the inefficiencies associated with circulation control at higher lift levels, where the lift gains diminish and the AFC performance becomes quite dismal. 
It is assumed that a slight reduction in mass flow could be achieved by substituting the CD nozzles with an equivalent system of FOs. This type of implementation was evaluated earlier for the original simplified configuration (Section V-A-4). The system of FOs was not considered for the revised geometry since it seems unlikely that it will achieve substantially smaller mass flow to meet the goal for a practical AFC system $\left(C_{q}\right.$ $=0.0001)$.

\section{Spanwise convergent-divergent nozzle}

The discrete nozzle system requires supply of very high pressure ratio. In fact, the $P R$ required to achieve the lift target exceeds typical APU or engine bleed capabilities. At this point, a different actuation system based on a continuous nozzle that runs the full span of the inboard flap will be investigated. The long nozzle system is described in Figure 16. It consists of a two-dimensional CD nozzle whose exit section forms a long slot along a backward facing step. The throat-area to inlet-area ratio is 0.4 , similar to the area ratio used in the multi nozzle systems from Sections V-A-3 and V-B-3. The inlet consists of a constant area duct which is connected to a convergent duct section. The upper walls of the two sections form a straight line. The diffuser is long enough to ensure that its half angle is smaller than $15^{\circ}$ to prevent flow separation. Figure $16 \mathrm{~b}$ presents the flow fields obtained for a set of inlet pressure ratios. At the low PR of 1.6, the nozzle is barely sonic and the subsonic jets are able to partially attach the flow. At $\mathrm{PR}=2.4$, the ejection jets are supersonic with a Mach number of about 1.4. The blanket of high speed flow helps energize the viscous layer and prevent flow separation over the entire flap element. Finally, the high speed jets at $\mathrm{PR}=3.2$ help in reducing the separation at the flap edges while providing added lift through circulation control. The lift gains in Figure 16c illustrate further reduction in mass flow is realized with the long nozzle relative to the system of CD nozzles. Moreover, it requires much lower operating pressure.

\section{Traverse actuation}

The traverse actuation method recently developed by Boeing ${ }^{7}$ has been used in order to further reduce actuation mass flow. It has been proven very effective for several applications in computational simulations. The method is based on an array of discrete jets blowing in the streamwise direction. The jets move in the spanwise direction. The continuous actuation produces small and fast moving jet packets, which travel periodically in the lateral direction, much like a crabwise motion. This spatial sweeping motion provides wide area coverage and is very effective in reducing flow separation.

The computational model used for the spanwise nozzle in the preceding section is extended to traverse actuation by applying special time-varying boundary conditions at the inlet face according to Reference 7 . A single wave packet (denoted w1) traversing the length of the nozzle at actuation frequencies of $10 \mathrm{H}_{\mathrm{z}}$ and $100 \mathrm{H}_{\mathrm{z}}$ are presented. Another actuation parameter, which determines the size of the jet, is also evaluated. The width of the jet is expressed in terms of the fraction of the nozzle being actuated at any point in time. The two jet sizes considered here are designated $\mathrm{p} 1 / 4$ and $\mathrm{p} 1 / 8$. As an example, the traverse actuation of $\mathrm{p} 1 / 8$-w 1 that operates at $10 \mathrm{H}_{\mathrm{z}}$ denotes a jet size equivalent to $1 / 8^{\text {th }}$ the length of the nozzle traversing the entire nozzle length every 0.1 seconds. The jet velocity is determined from PR, just like in the case of the constant blowing spanwise nozzle. However, a time-varying signal of PR is applied at the inlet to simulate the traversing wave.

Figure 17 shows the instantaneous flow structure obtained with the two jet sizes at the two frequencies. The computed flow fields of the unactuated and the steady blowing with the spanwise nozzle cases are also shown for reference. The ejection jets are represented by the bundle of streamwise pointing vectors and they traverse the nozzle in the inboard direction.

The flow mechanism provided by the traversing jet is easy to interpret from the $10 \mathrm{H}_{\mathrm{z}}$ actuation patterns. The cross-flow motion produces momentary flow attachment in the region around the respective wing section. A lingering effect occurs when the jet operates at a frequency of $10 \mathrm{H}_{\mathrm{z}}$. The flow remains attached over sizeable wing segments, which is larger than the width of the active jet and extends to the trailing edge. The instantaneous pockets of attached flow are denoted by 'a' and exhibit a slanted pattern, consistent with the jet traveling inboard. The continuous actuation results in improved streamlining of the flow at the flap in a time-average sense. It also creates 
an induced ripple effect that helps attach the flow over the outboard wing segment. The combined effects increase global circulation which results in greater lift production as seen from the surface pressure distributions.

A discussion on the effect of the actuation frequency in the context of traverse jets is in order. The lateral motion aims at killing off the separation in front of the jet packet. However, the flow reverts to its original separated state behind the jet packet. The traverse actuation exploits the flow latency during the reversion to the original flow separation state. At the appropriate actuation frequency (i.e., jet lateral speed), the jet is able to cut into the separation bubble in the front at a greater rate than the regeneration of the separation pocket in the back. Moreover, the reversion to the original separation state is delayed by the following jet packet. Not surprisingly, improved flow is obtained with the $10 \mathrm{~Hz}$ actuation frequency, which is consistent with the characteristics time scale of the flow.

The actuation at $100 \mathrm{H}_{\mathrm{z}}$ is less effective with limited impact on the separation pattern. In this case, the interaction between the oscillatory jet and the ambient flow is virtually invariant on the global time scale and therefore, the flow on the flap is effectively decoupled from the operating frequency. Similarly, low frequency actuation of $5 \mathrm{H}_{\mathrm{z}}$ also results in relatively limited improvement, in which case, the jet cuts into the separation bubble in the front at a slower rate than the regeneration of the separation in the back. The results of the low frequency actuation are not included here.

Figure 18 shows the lift gains due to traverse actuation versus mass flow. The performance of the traverse actuation patterns represents an improvement relative to the blowing nozzle case. However, meaningful advantage is provided with the $10 \mathrm{H}_{\mathrm{z}}$ actuation frequency. This frequency results in favorable coupling between the flow control excitation and the surrounding flow, with commensurate mass flow reduction, between $3 \mathrm{lb} / \mathrm{sec}$ and $4 \mathrm{lb} / \mathrm{sec}$ at an operating pressure ratio of 2.4. These actuation parameters are considered practical and within onboard supply limits.

\section{Conclusion}

The goal of the current study is to develop a low input actuation technique to address a key requirement in the design of onboard AFC systems. The flow control is used in conjunction with a simplified high-lift configuration that offers significant airplane performance improvements. A computational model that has been extensively validated for numerous AFC applications is used to evaluate the flow control approaches. The study focuses on AFC techniques, which require onboard fluidic sources since those are most effective for the control of large separated flows. The methods include steady blowing devices and actuators, which produce unsteady flow excitations. The computational simulation indicate that several AFC approaches are capable of achieving the target lift level at a nominal landing condition. However, reducing the mass flow required for actuation to practical levels within available resources onboard is a major challenge.

A systematic approach is used to identify candidate low input actuation methods. It has led to an implementation of the traverse actuation method, which is applied on the inboard flap element. The low input solution is especially effective when the actuation frequency is comparable to the characteristics time scale of the global flow. This facilitates proper interaction between the global flow and the control jet, with substantial impact on the flap flow and lift production. Although the simulations of the traverse jets show promising results, honing designs for higher actuation efficiency is highly desirable. A potential refinement is the split wave variant which results in a more even distribution of perturbations along the span ${ }^{7}$. It is noted, however, that the integration of the new actuation method hinges upon a successful implementation of a traverse actuator system. Devices for generating traversing jets are currently under development. The experimental validation of the traverse actuation method will be conducted at the NASA 14x22 wind tunnel facility in 2018 within the framework of the Advanced Air Transport Technology Project $^{6}$.

\section{Acknowledgments}

This study was sponsored by NASA under Contract NNL10AA05B / NNL14AB98T. Dr. John C. Lin was the NASA Langley Research Center Task Principal Investigator. 


\section{References}

${ }^{1}$ McLean, J.D., Crouch, J.D., Stoner, R.C., Sakarai, S., Seidel, G.E., Feifel, W.M., and Rush, H.M., "Study of the Application of Separation Control by Unsteady Excitation to Civil Transport Aircraft," NASA Contractor Report, NASA-CR-1999-209338, June 1999.

${ }^{2}$ Hartwich, P.M., Camacho, P.P., El-Gohari, K., Gonzales, A.B., Lawson, E.L., Shmilovich, A., "System-Level Trade Studies for Transonic Transports with Active Flow Control (AFC) Enhanced High-Lift Systems," To be presented at the 2017 AIAA SciTech Conference.

${ }^{3}$ Collier, F. S., Thomas, R., Nickol, C. A., Lee, Chi-Ming, and Tong, M., "Environmentally Responsible Aviation - Real Solutions for Environmental Challenges Facing Aviation," 27th International Congress of the Aeronautical Sciences, Paper No. 802, Nice, France, September 19-24, 2010.

${ }^{4}$ Bezos-O'Conner, G. M., Mangelsdorf, M. F., Maliska, H. A., Washburn, A. E., and Wahls, R. A., "Fuel Efficiencies Through Airframe Improvements," AIAA 2011-3530.

${ }^{5}$ Whalen, E., Shmilovich, A., Spoor, M., Tran, J., Vijgen, P., Lin, C.J. and Andino, M., "Full-scale Flight Demonstration of an Active Flow Control Enhanced Vertical Tail,” AIAA Paper 2016-3927.

${ }^{6}$ Lin, C.J., Melton, L.P., Viken, S.A., Andino, M., Koklu, M., Hannon, J.A., and Vatsa, V.N., "High Lift Common Research Model for Wind Tunnel Testing: An Active Flow Control Perspective," To be presented at the 2017 AIAA SciTech Conference.

${ }^{7}$ Shmilovich, A. and Yadlin, Y., "Traverse Actuation method," AIAA Paper 2016-3309.

${ }^{8}$ Vassberg, J.C., DeHaan, M.A., Rivers, S.M. and Wahls, R.A., "Development of a Common Re-search Model for Applied CFD validation," AIAA Paper 2008-6919.

${ }^{9}$ Buning, P.G., Chiu, I. T., Obayash, S., Rizk, Y., M., and Steger, J., L., "Numerical Simulation of the Integrated Space Shuttle Vehicle in Ascent", AIAA Paper 1988-4359.

${ }^{10}$ Shmilovich, A. and Yadlin, Y., "Flow Control for the Systematic Buildup of High Lift Systems," Journal of Aircraft, Vol. 45, No. 5, 2008, pp. 1680-1688.

${ }^{11}$ Shmilovich, A. and Yadlin, Y., "Active Flow Control for Practical High Lift Systems," Journal of Aircraft, Vol. 46, No.4, 2009, pp. 1354-1364.

${ }^{12}$ Khodadoust, A. and Shmilovich, A., "High Reynolds Numbers Simulations of Distributed Active Flow Control for a HighLift System," AIAA Paper 2007-4423.

${ }^{13}$ Shmilovich, A. and Yadlin, Y., "Flow Control Techniques for Transport Aircraft," AIAA Journal, Vol. 49, No 3, 2011 , pp. 489-502.

${ }^{14}$ Yadlin, Y. and Shmilovich, A., "Lift Enhancement for Upper Surface Blowing Airplanes,” AIAA Paper 2013-2796.

${ }^{15}$ Shmilovich, A., Yadlin, Y. and Whalen, E., "Computational Evaluation of Flow Control for Enhanced Control Authority of a Vertical Tail,” AIAA Journal, Vol. 54, No 8, 2016, pp. 2211-2220.

${ }^{16}$ Shmilovich, A., Yadlin, Y. and Whalen, E., "Numerical Simulations of an Airplane with an Active Flow Control System", AIAA Paper 2016-3929.

${ }^{17}$ Seele, R., Graff, E., Gharib, M., Taubert, L., Lin, J. and Wygnanski, I.L., "Improving Rudder Effectiveness with Sweeping Jet Actuators," AIAA Paper 2012-3244.

${ }^{18}$ Seele, R., Graff, E., Lin, J. and Wygnanski, I.L., "Performance Enhancement of a Vertical Tail Model with Sweeping Jet Actuators," AIAA Paper 2013-0411.

${ }^{19}$ Vatsa, V. N., Koklu, M., Wygnanski, I.L. and Fares, E., "Numerical Simulation of Fluidic Actuators for Flow Control Applications," AIAA Paper 2012-3239.

${ }^{20}$ Melton, L. P. and Koklu, M., "Active Flow Control Using Sweeping Jet Actuators on a Semi-Span Wing Model," AIAA Paper 2016-1872. 

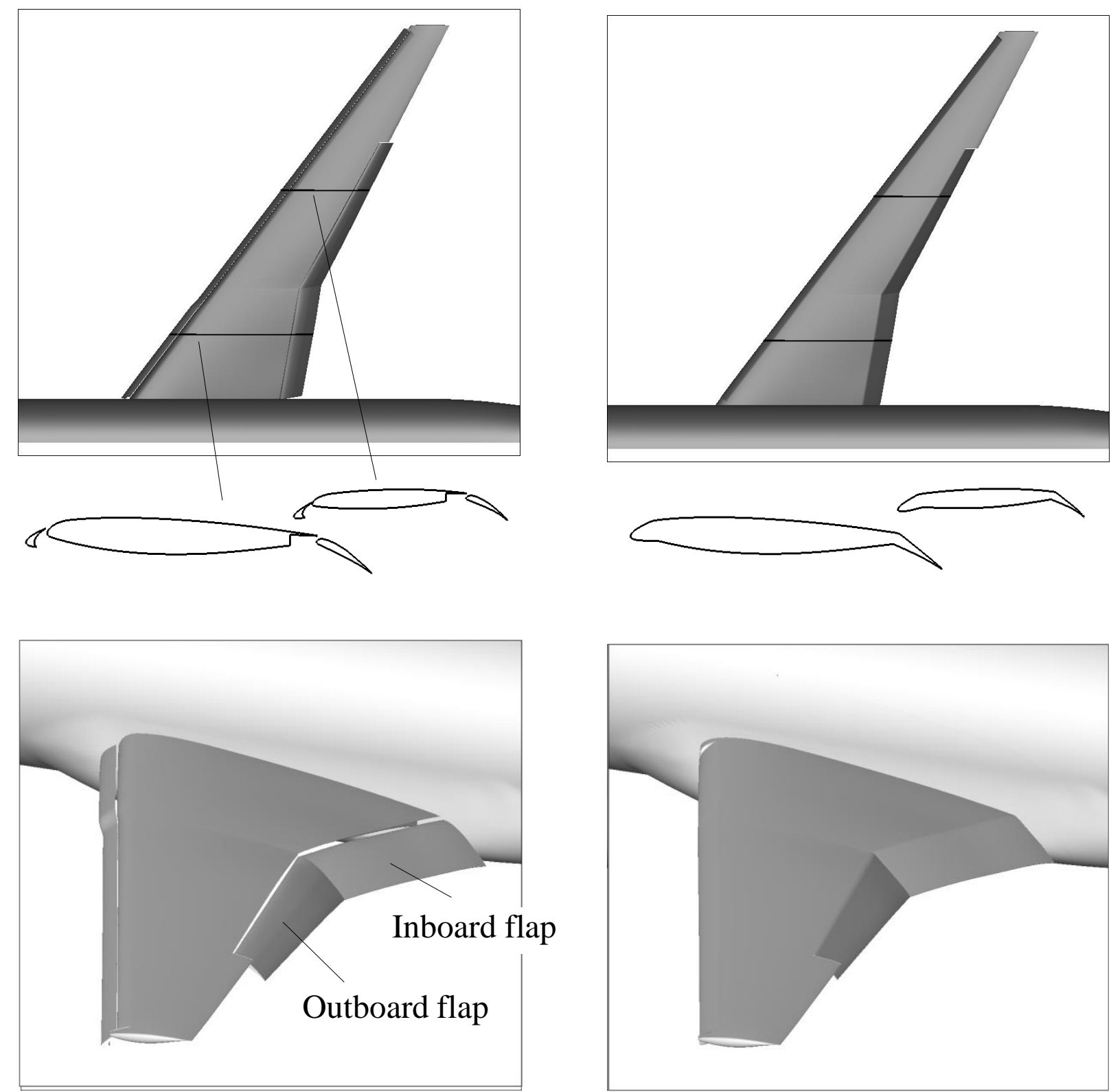

(a) Conventional

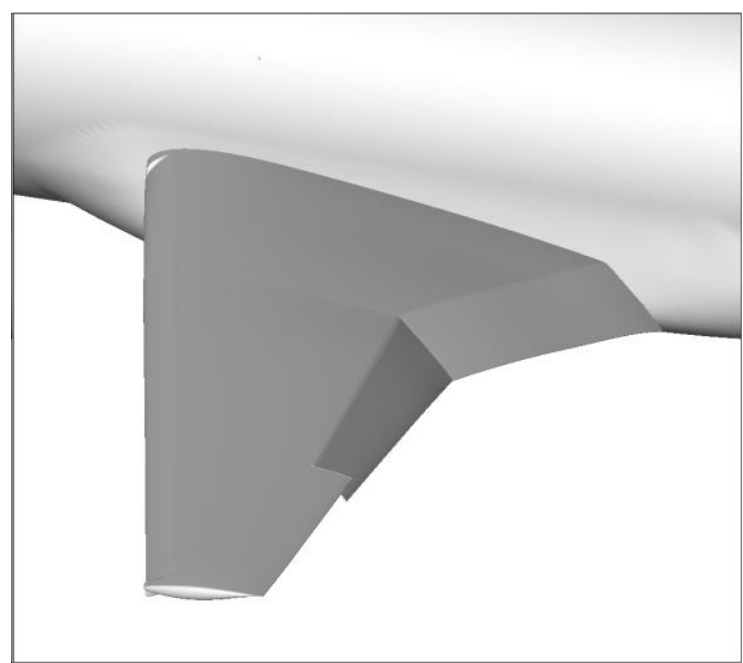

(b) Simplified

Figure 1. High-lift systems in the landing configuration, $\delta_{f}=30^{\circ}$. 


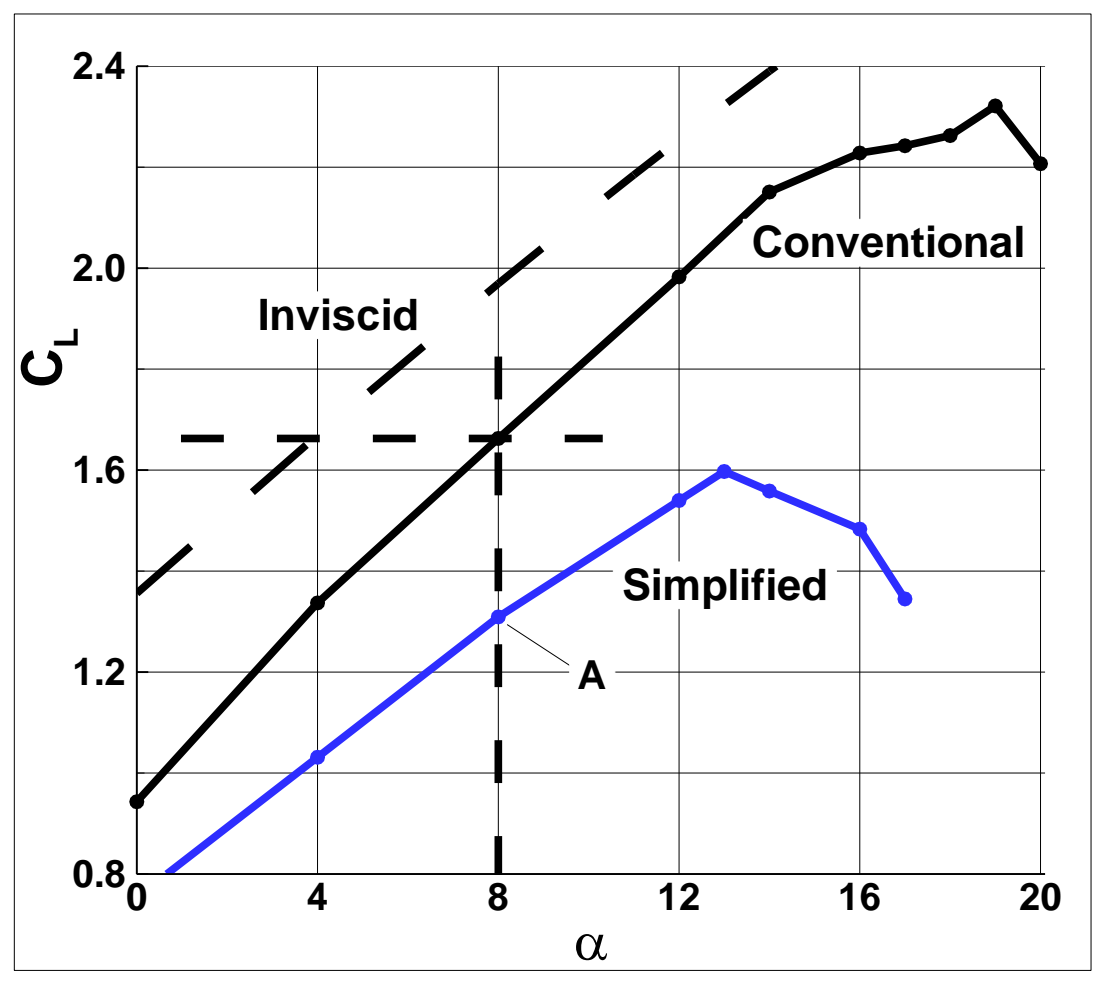

(a) Lift

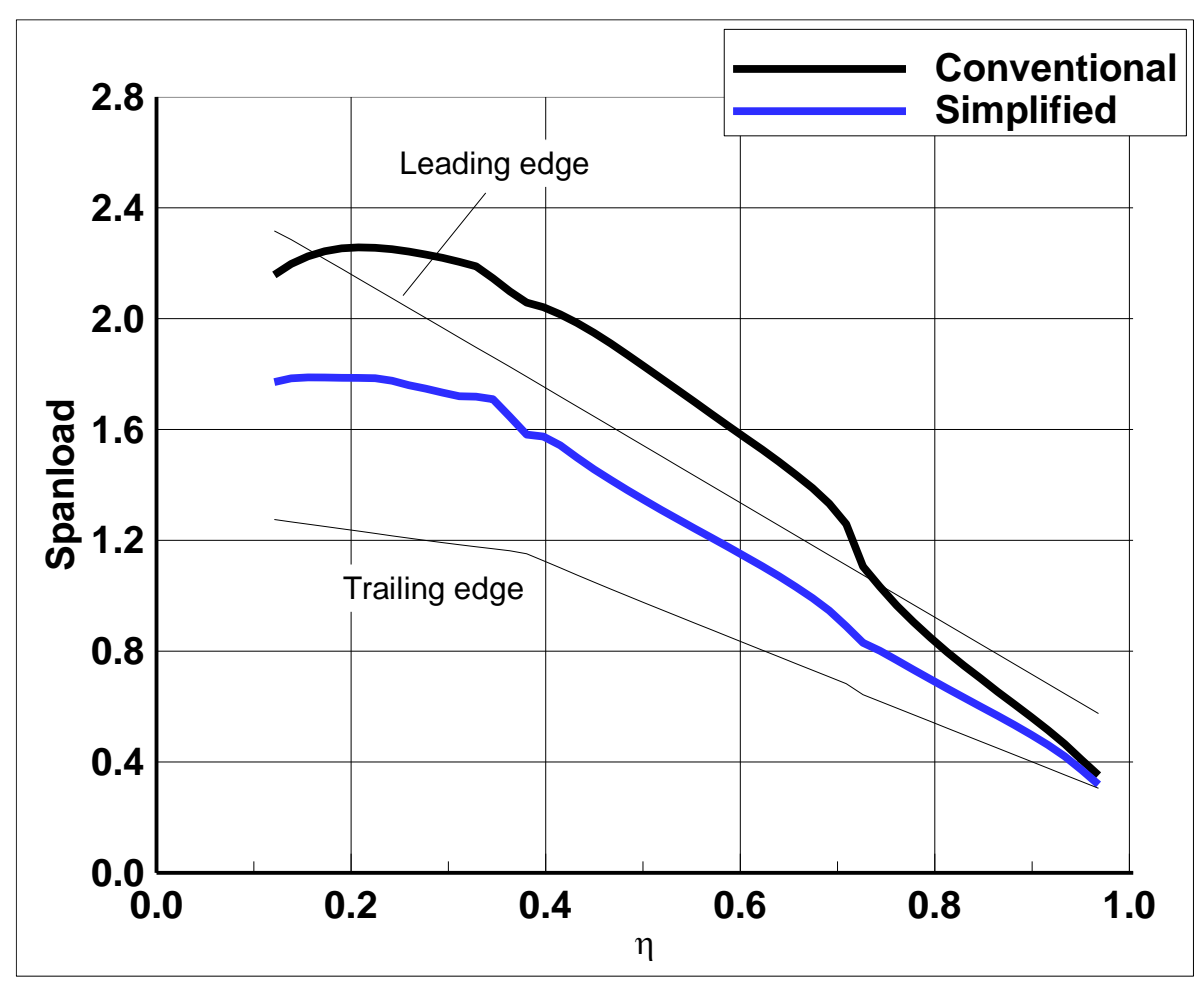

(b) Span load distribution

Figure 2. Performance of the high-lift systems in the landing configuration. 


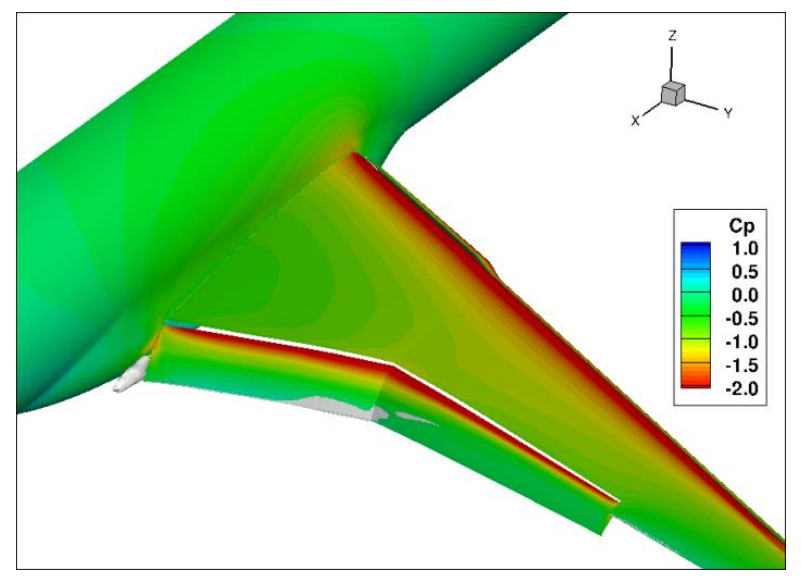

(a) Conventional

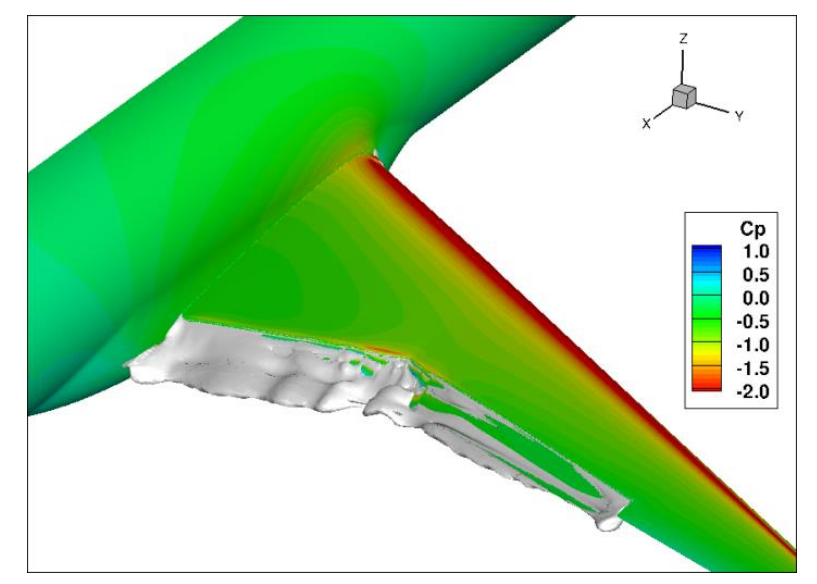

(b) Simplified

Figure 3. Flow fields of the high-lift systems, $\alpha=8^{\circ}$. 

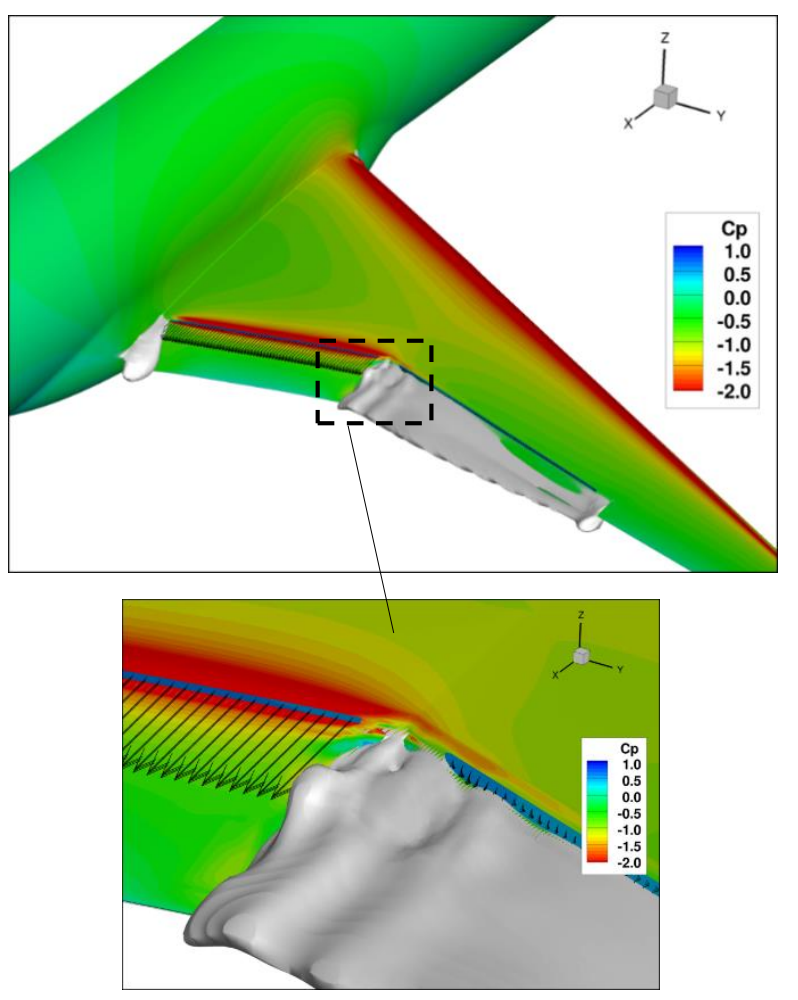

(a) Inboard
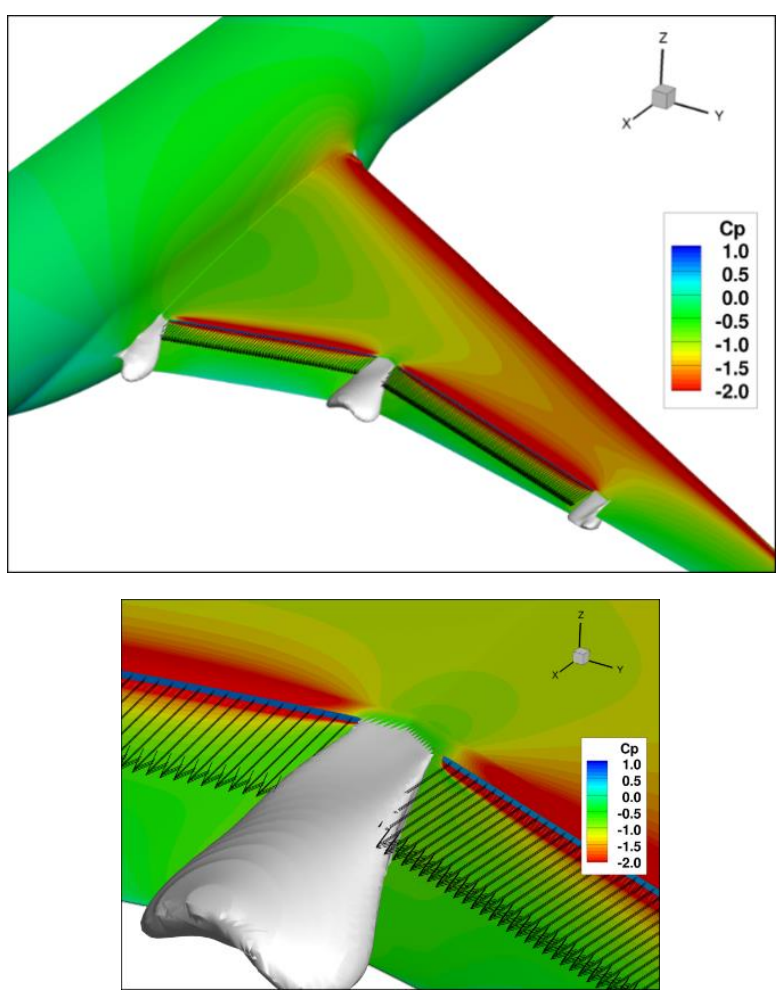

(b) Inboard + outboard
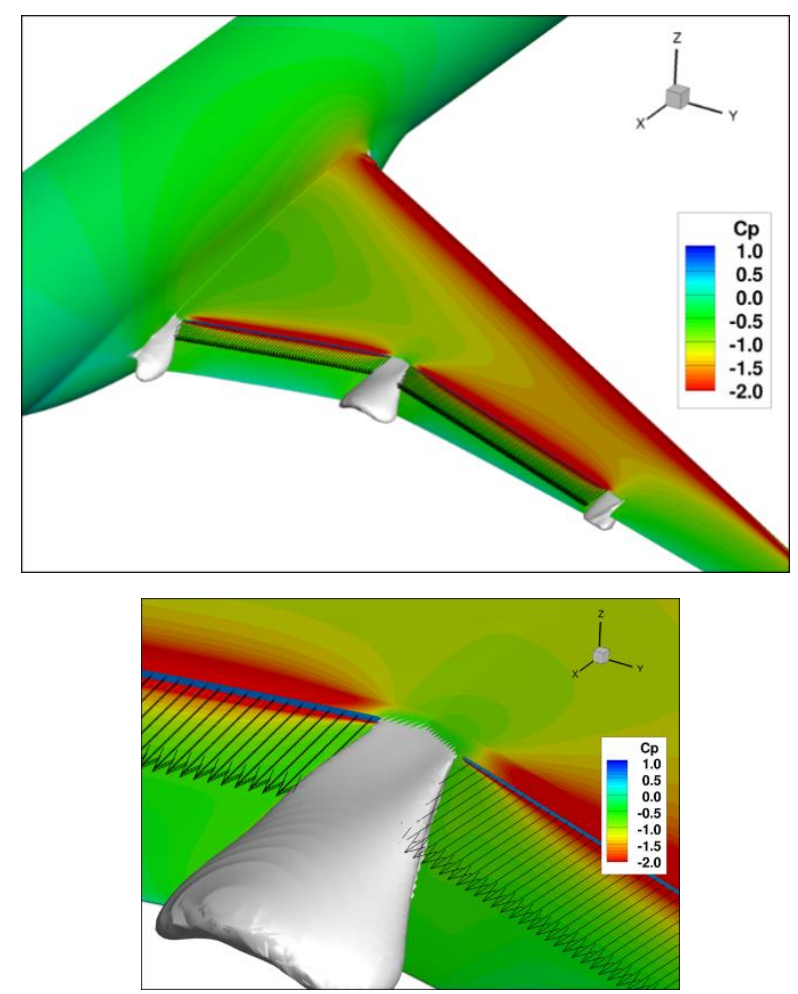

(c) Inboard + smaller outboard

Figure 4. Flow fields for the constant blowing flow control at nominal landing condition. 


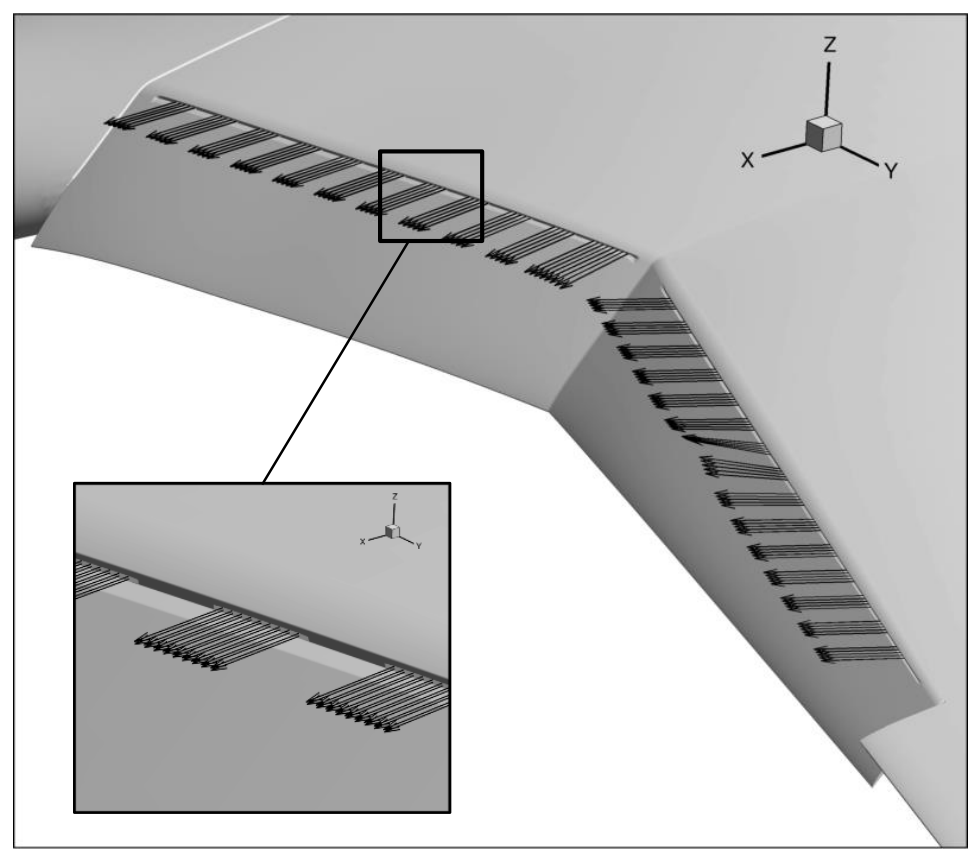

Figure 5. Embedded backward-facing step for actuators. 


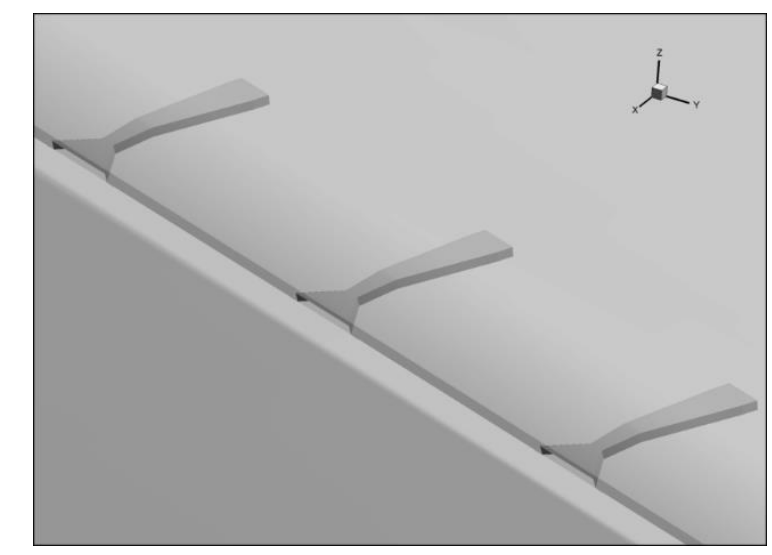

(a) Actuators mounted on the backward-facing step

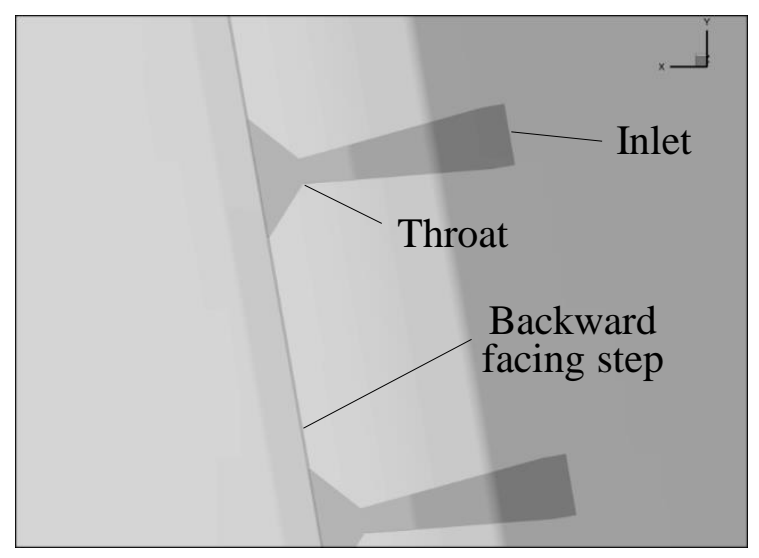

(b) Actuator geometry (top view)

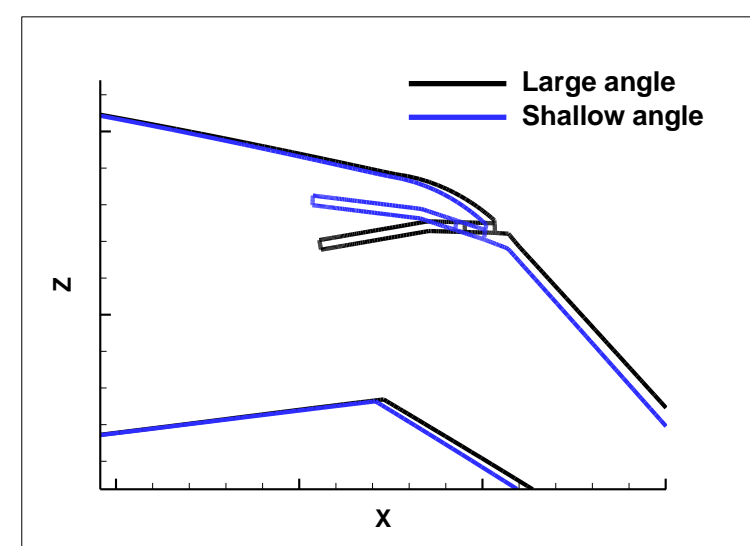

(c) Cut through actuators (mid inboard flap)

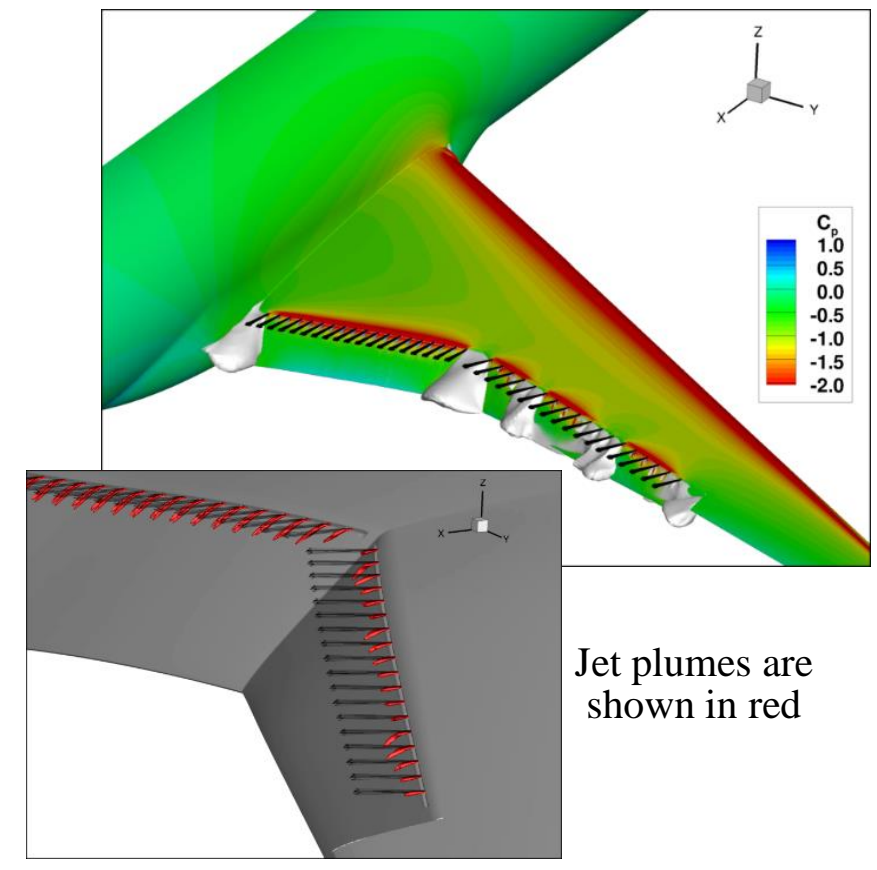

(d) Actuators at large angle to the surface

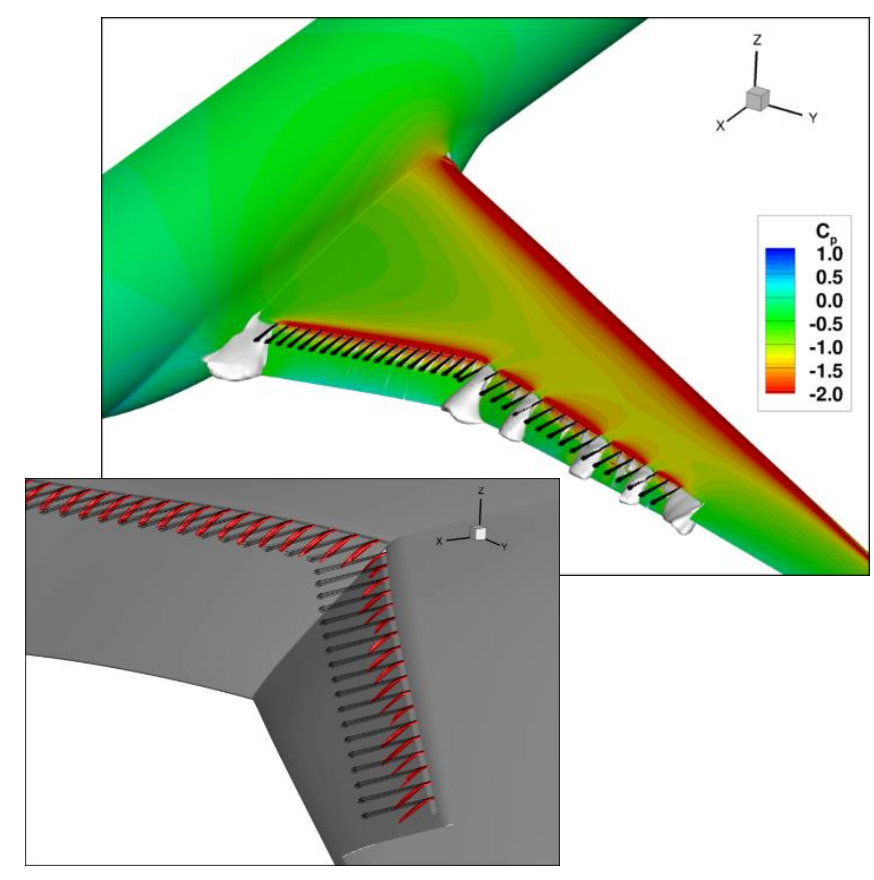

(e) Actuators at shallow angle to the surface

Figure 6. Discrete actuator model - convergent-divergent nozzles. 


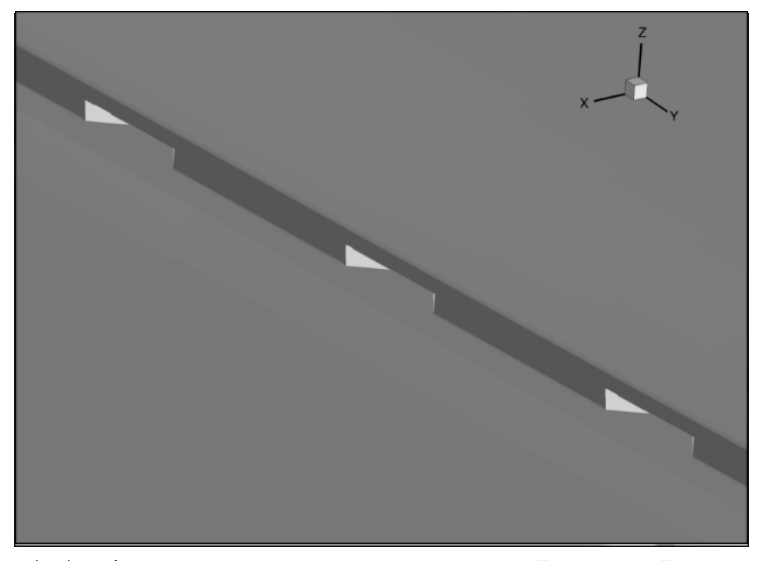

(a) Actuators mounted on the backward-facing step

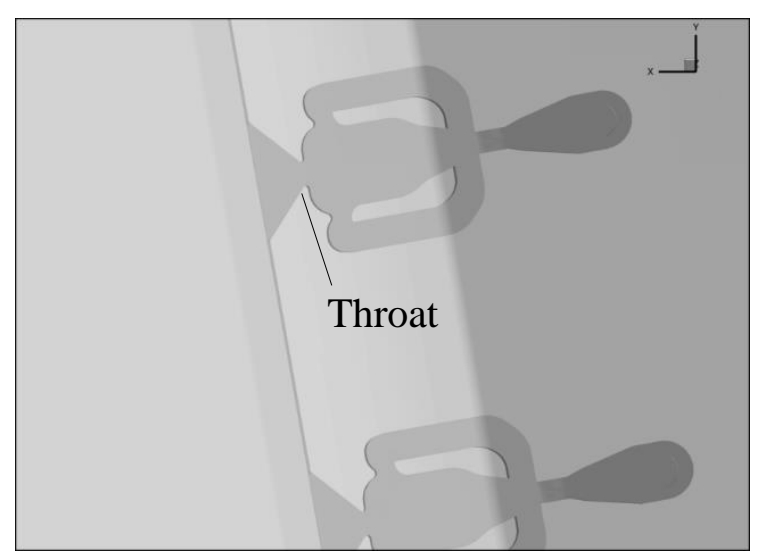

(b) Actuator geometry (top view)

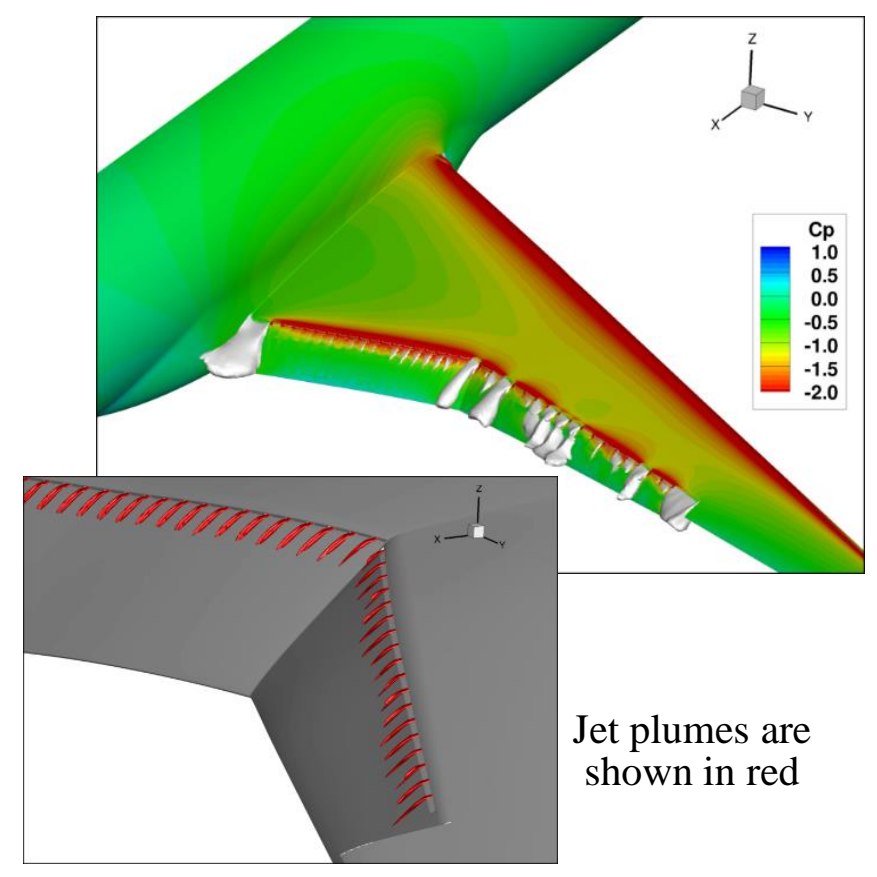

(c) Instantaneous flow field

Figure 7. Discrete actuator model - Fluidic Oscillators. 


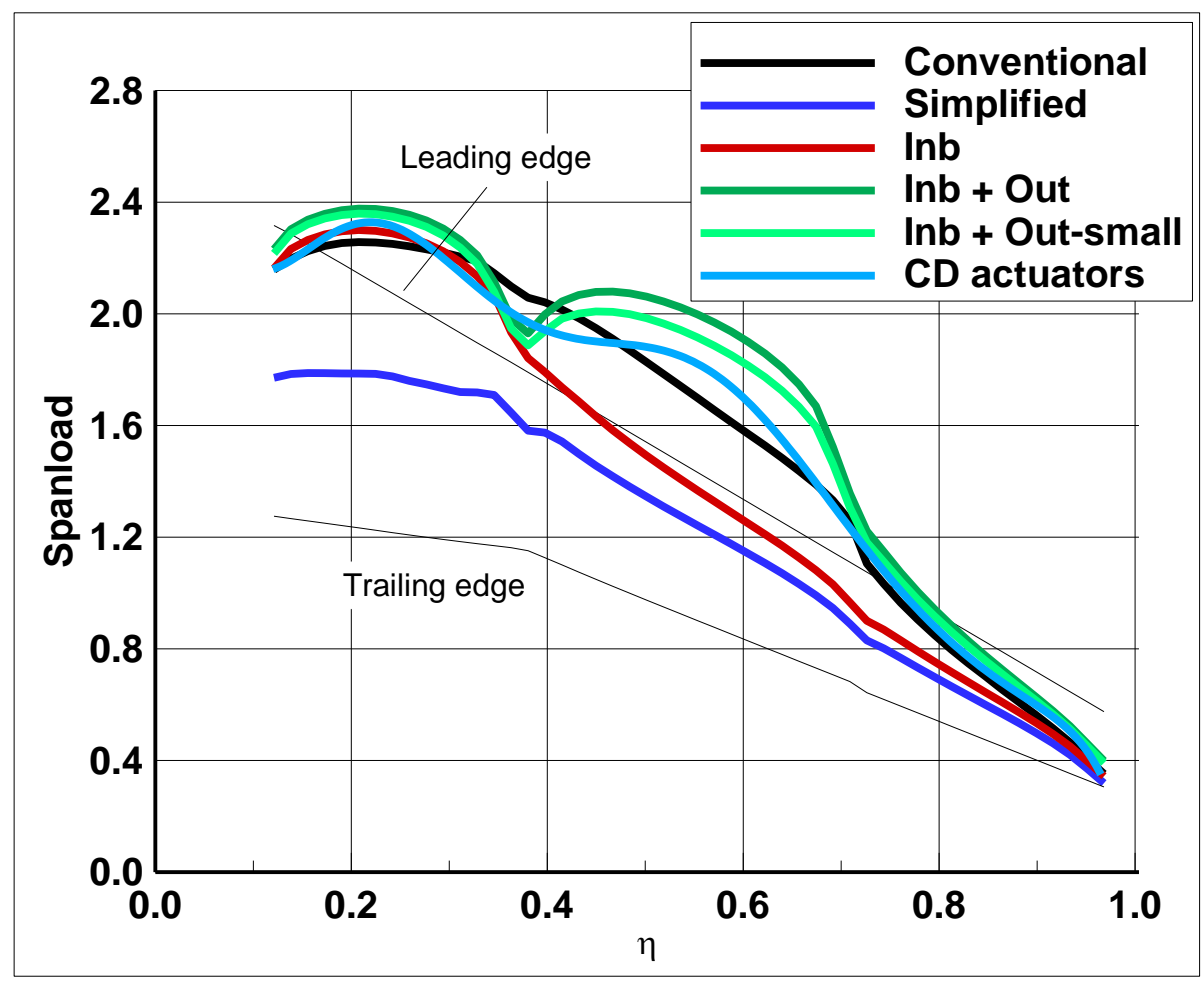

(a) Span load distribution

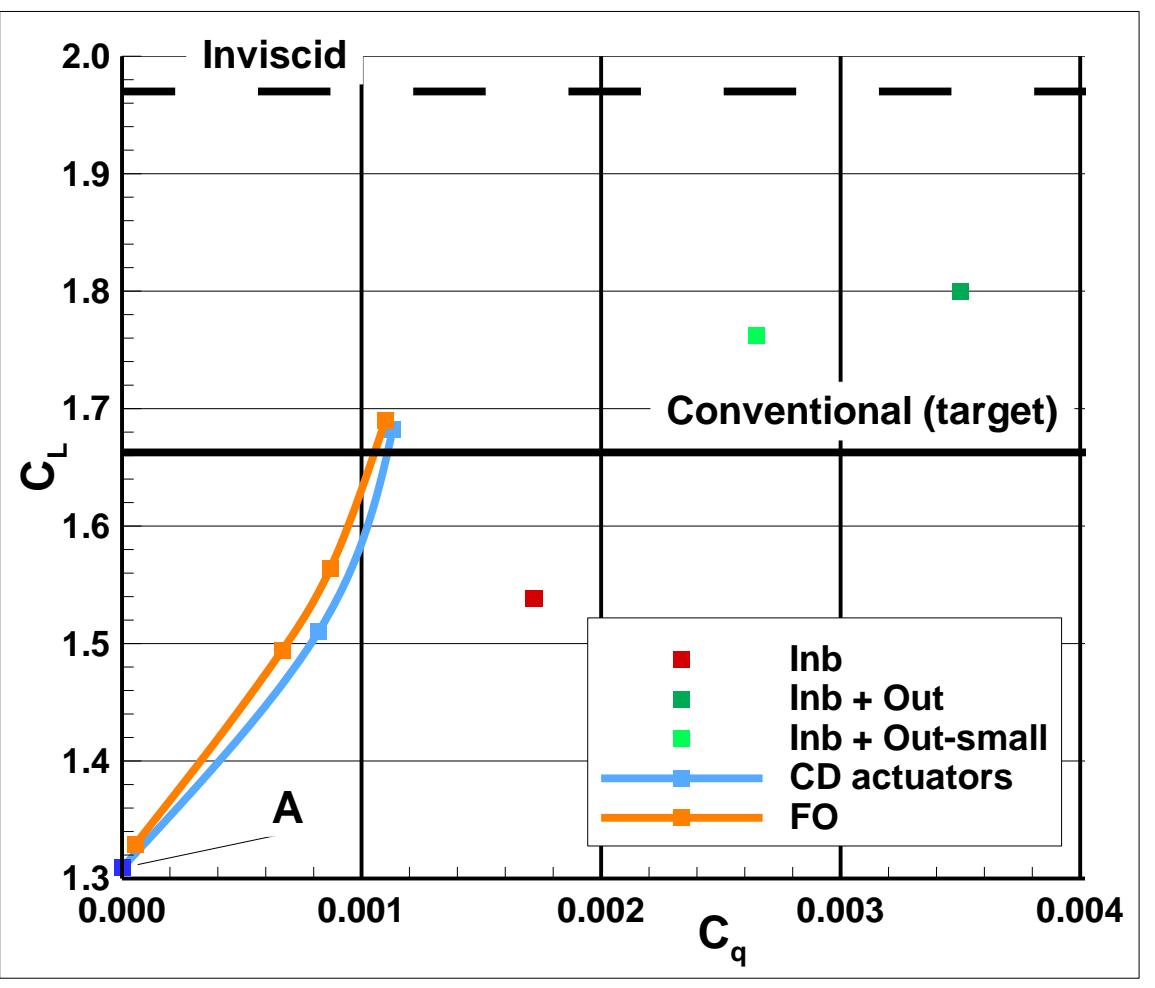

(b) Lift vs mass flow rate

Figure 8. Performance of various AFC patterns. 


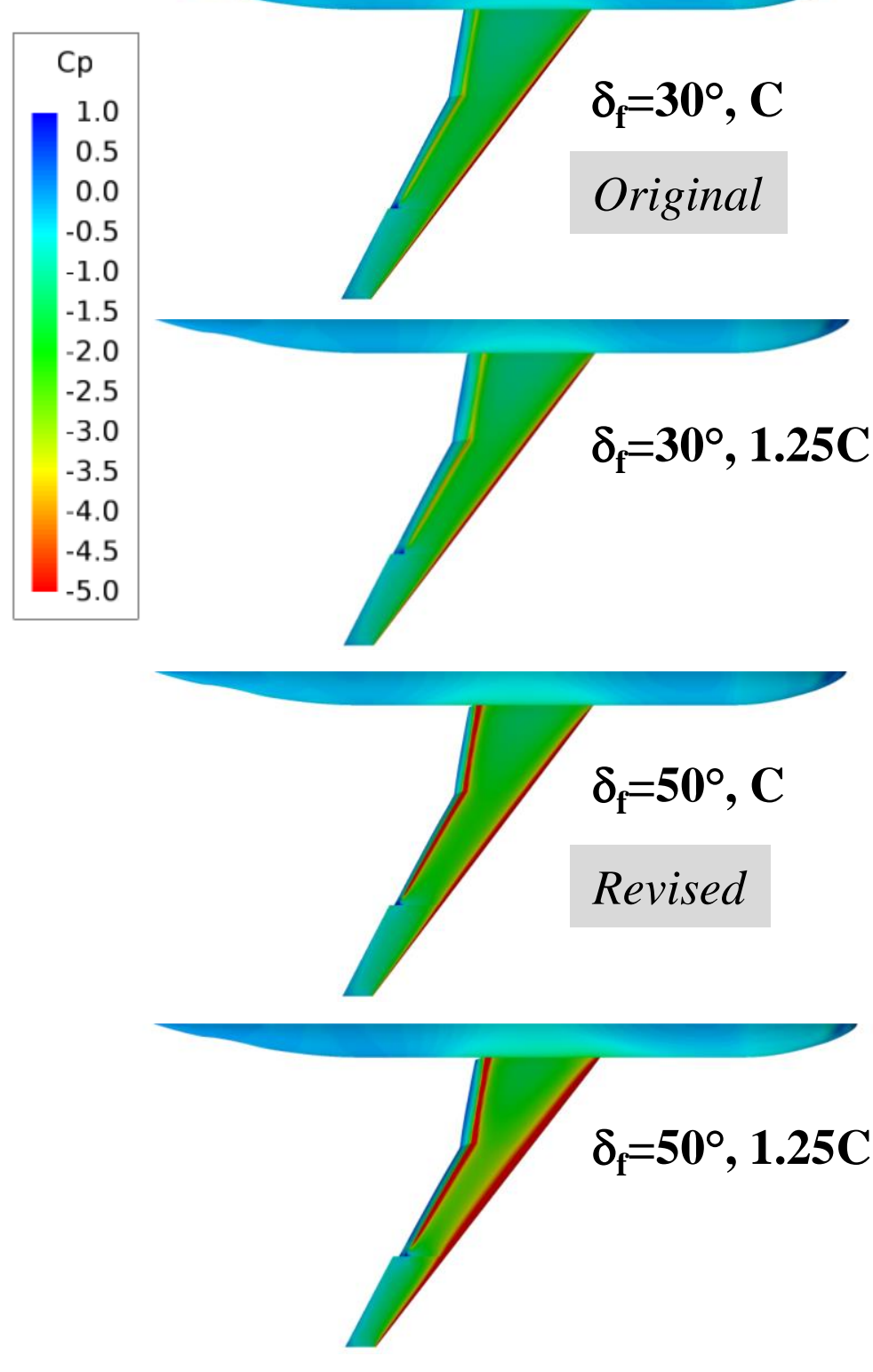

(a) Surface pressure distributions

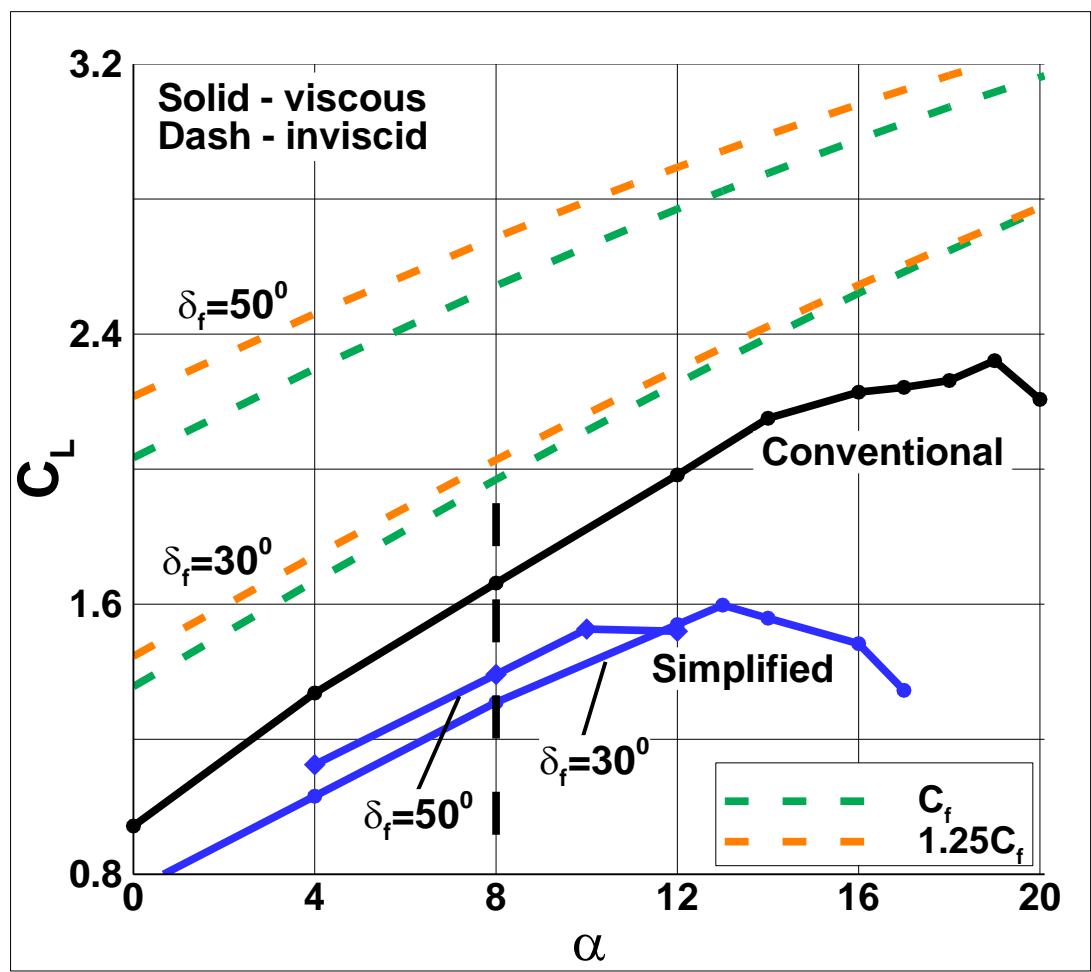

(b) Lift

Figure 9. Inviscid flow solutions for parametric evaluation of flap layout of the simplified configuration. 


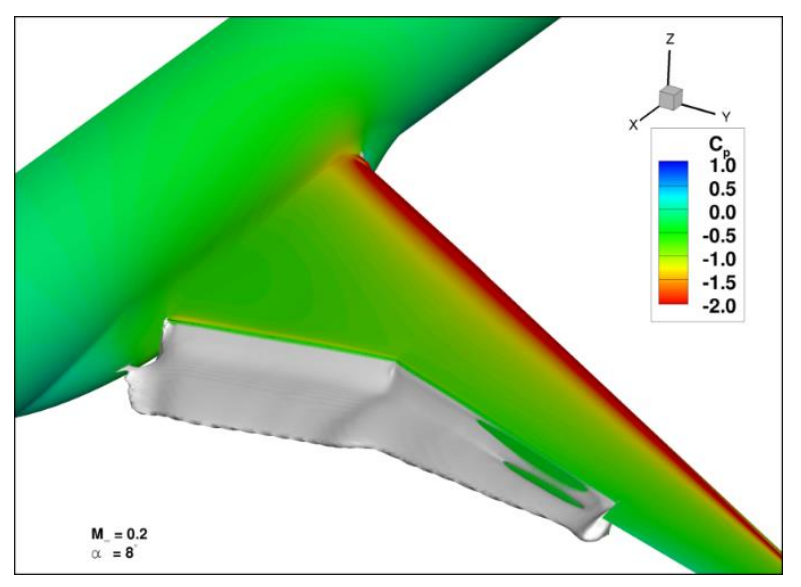

(a) Conventional

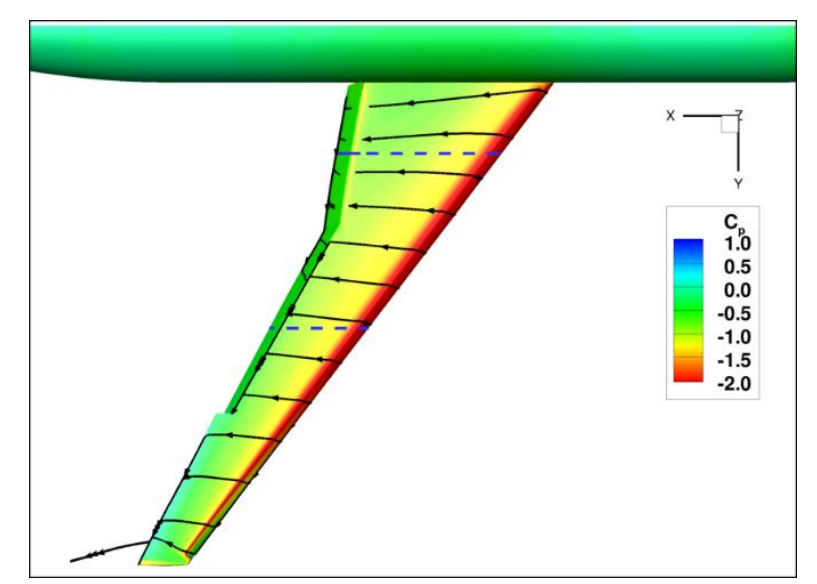

(b) Top view

Figure 10. Flow field of the revised simplified configuration with the flap at $50^{\circ}$ $\left(\alpha=8^{\circ}\right)$. 


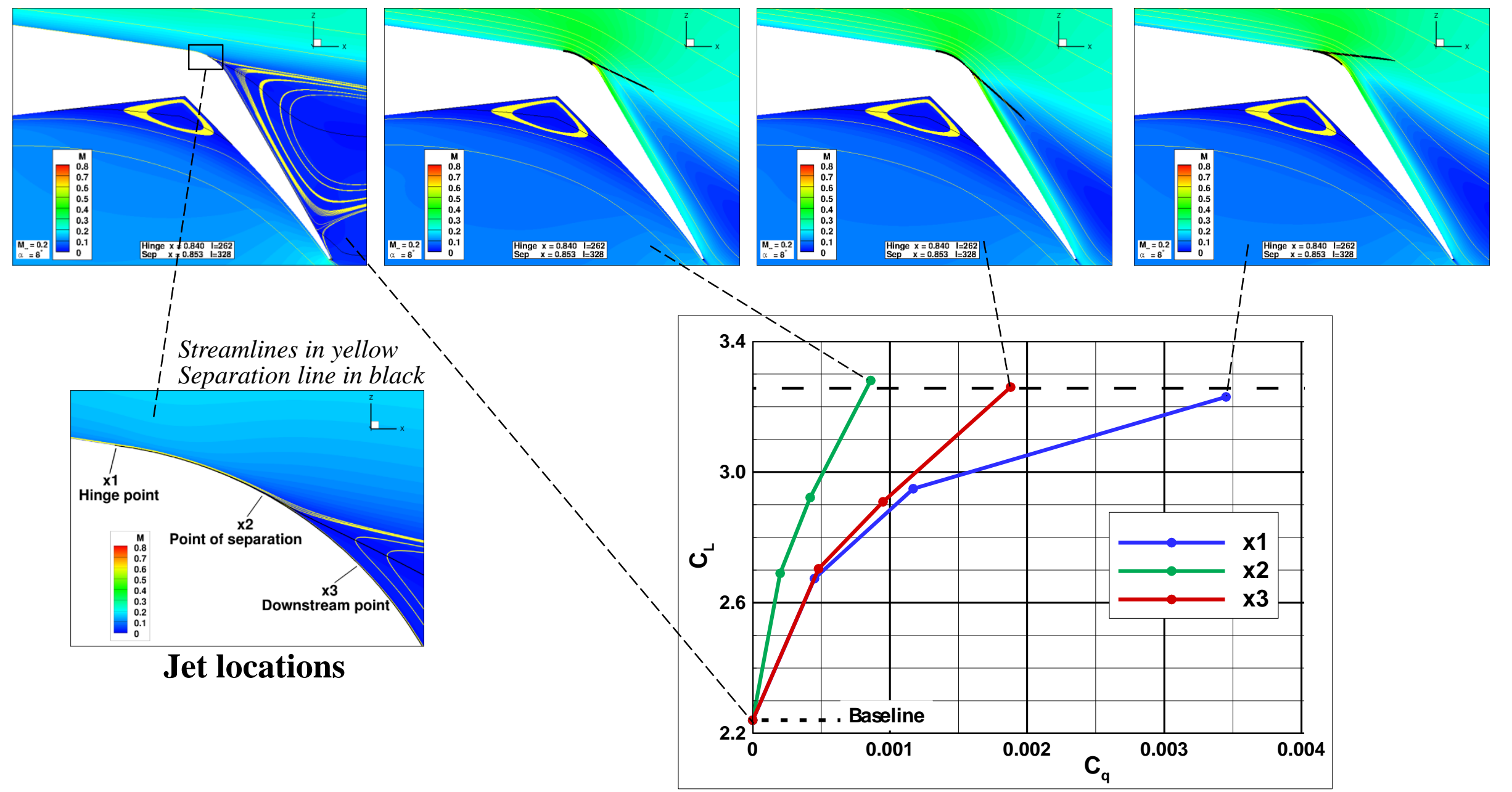

Figure 11. Analysis for mid section of inboard flap of the revised configuration $\left(\alpha=8^{\circ}\right)$. 


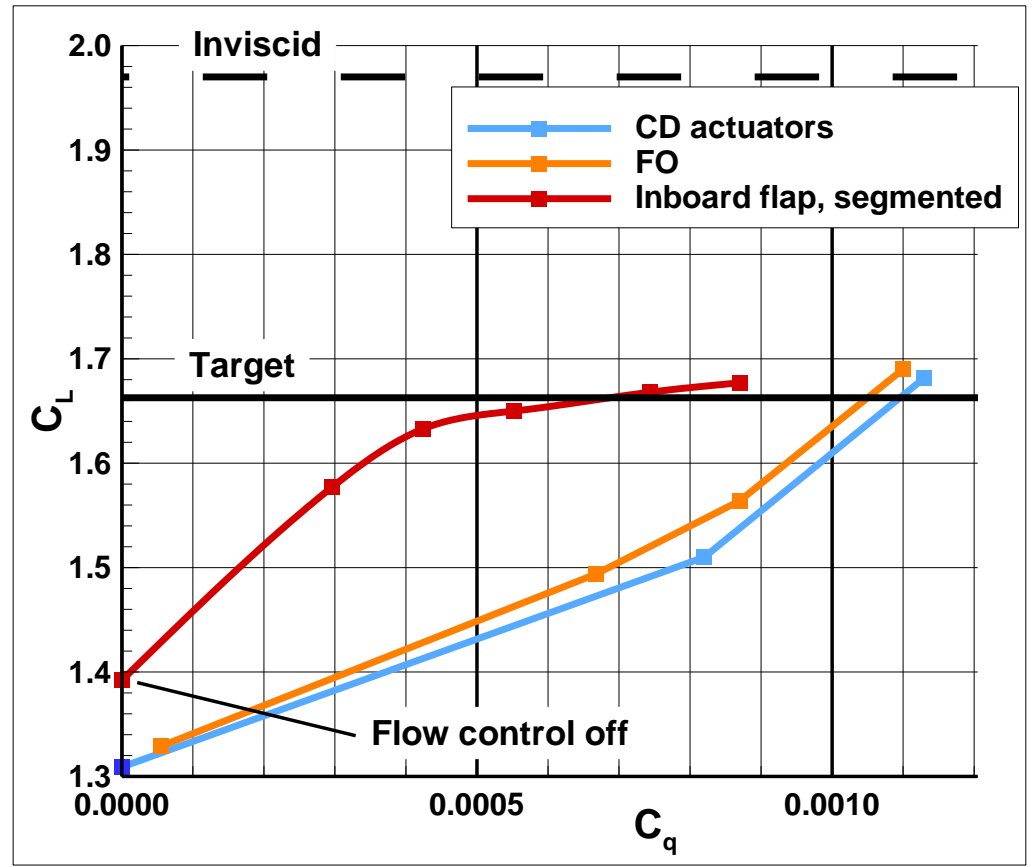

(a) Lift vs mass flow

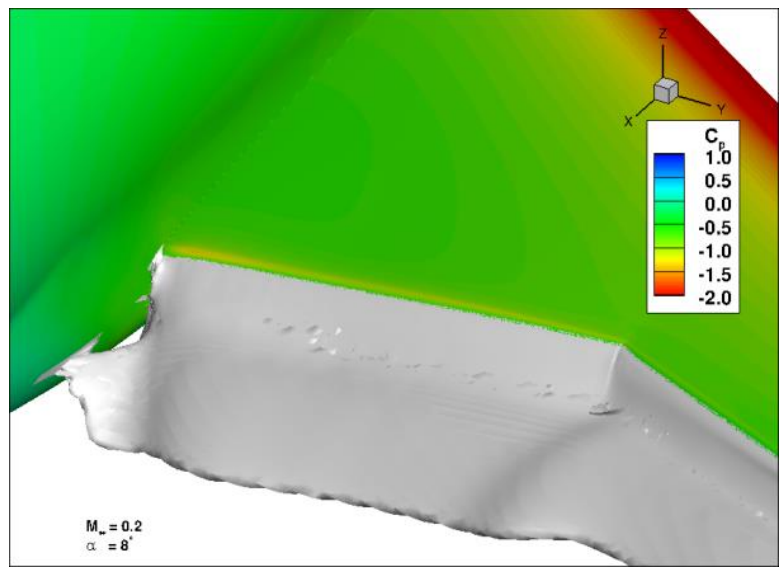

(c) Flow control off

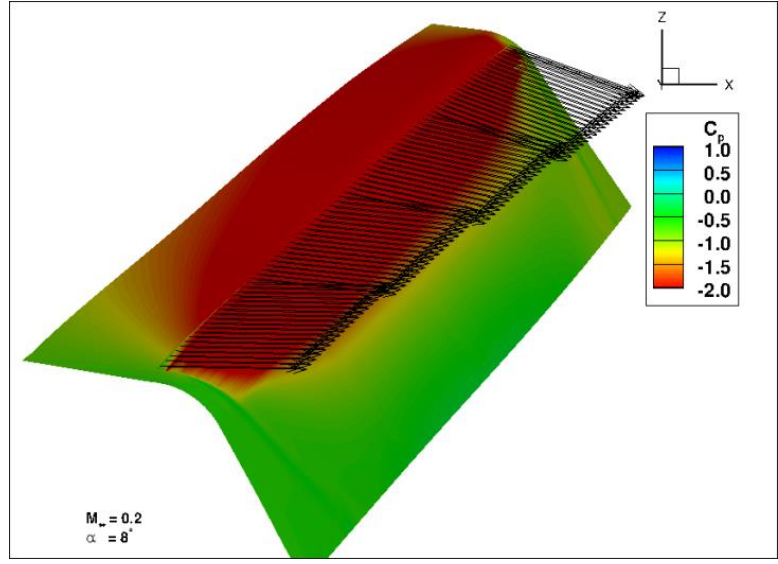

(b) Jet efflux

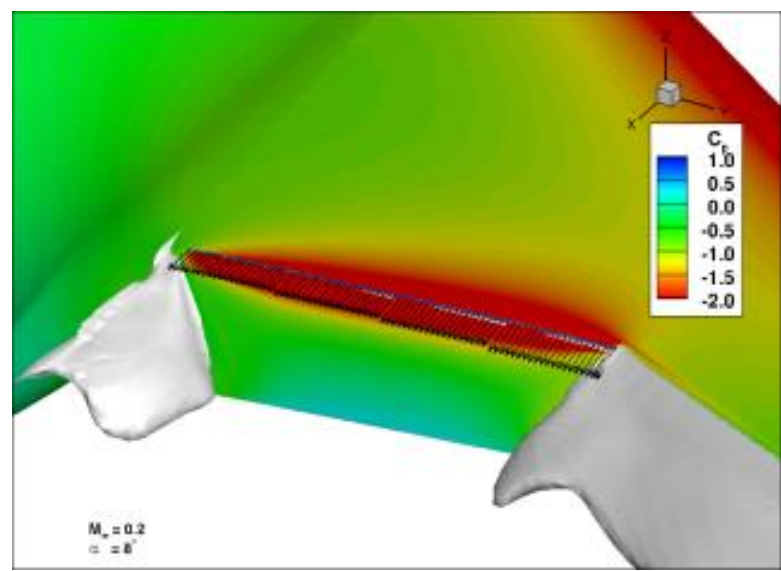

(d) Flow control

Figure 12. Constant blowing on the inboard flap of the revised configuration. 


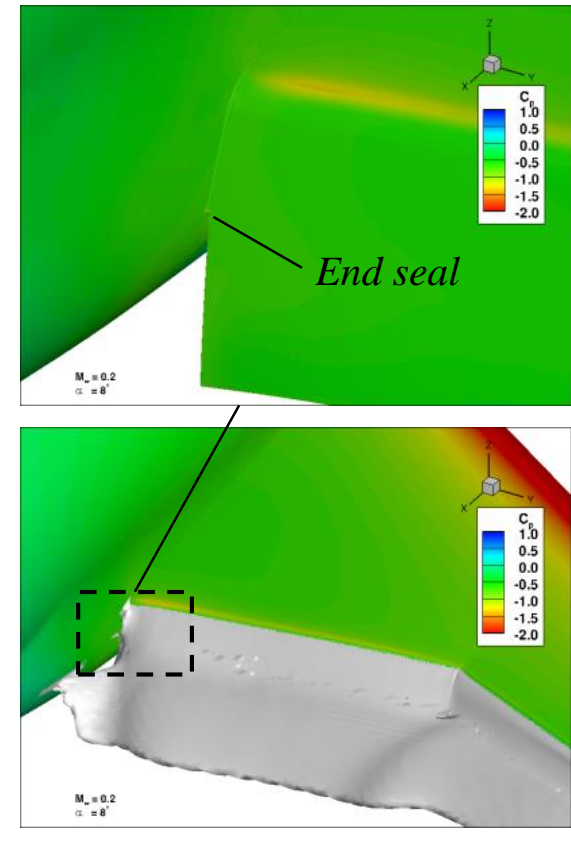

Flow control off

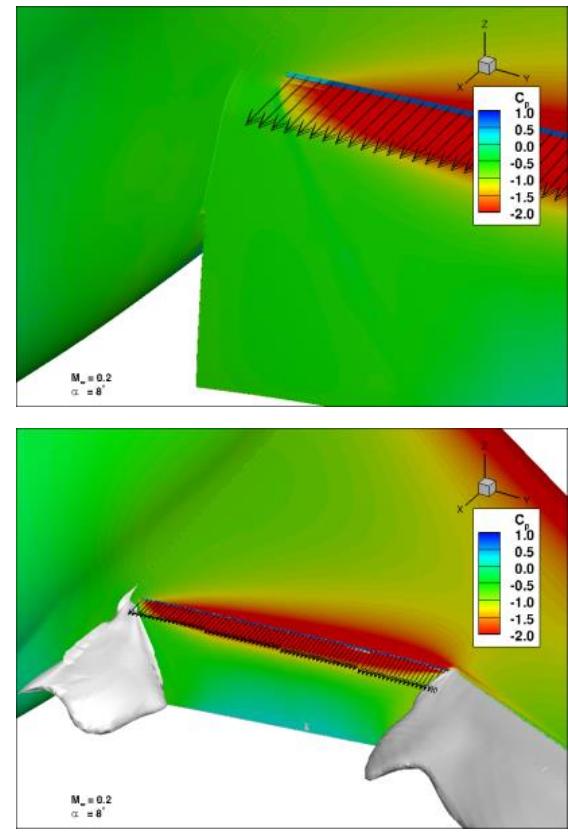

Flow control
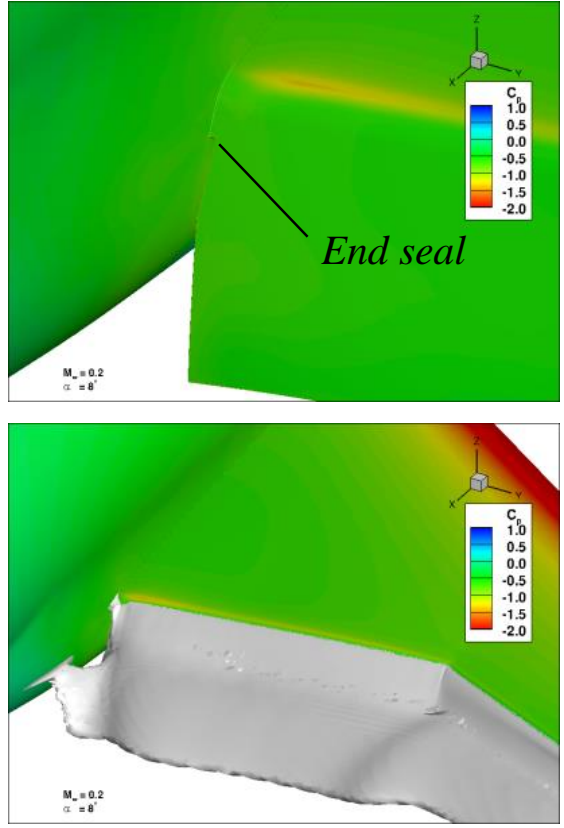

Flow control off
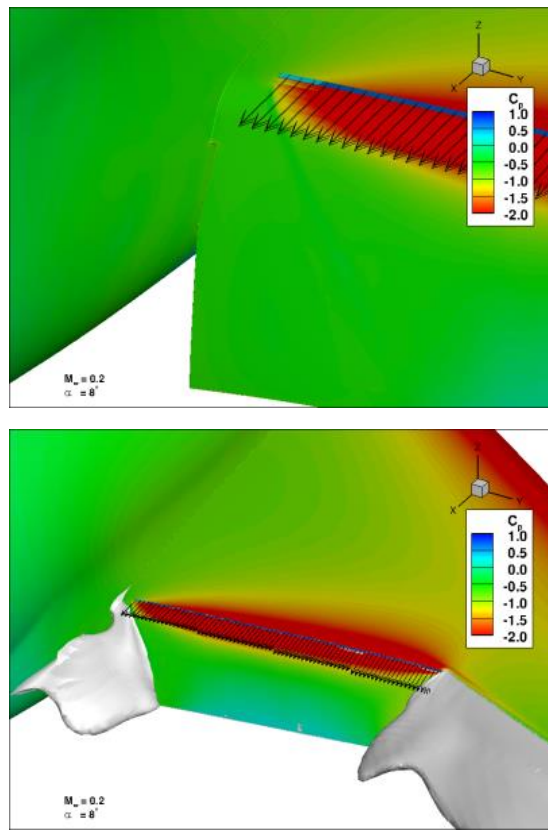

Flow control

(a) Long seal segment

(a) Short seal segment

Figure 13. Effect of the extent of the of the seal at the fuselage-flap junction. 


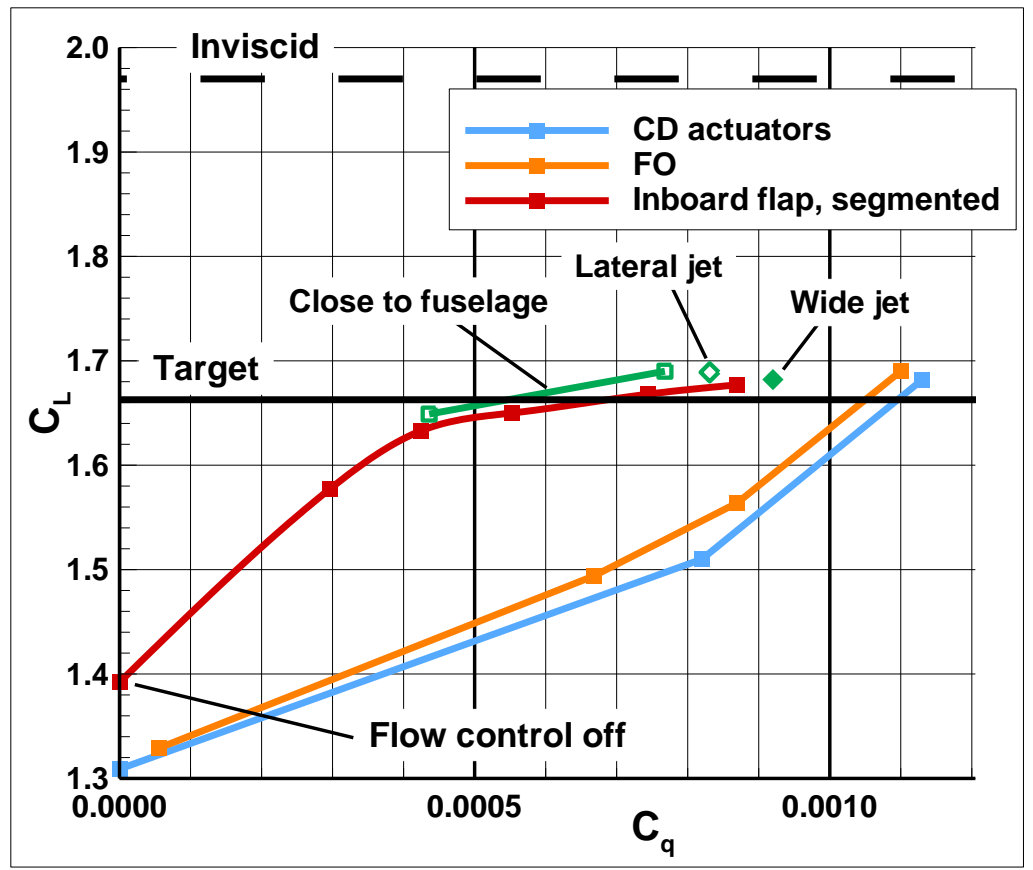

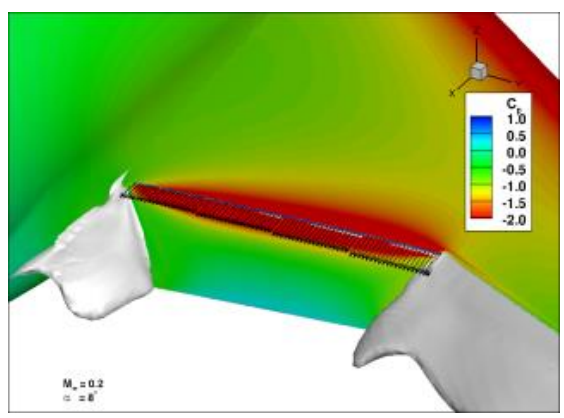

Flow control off

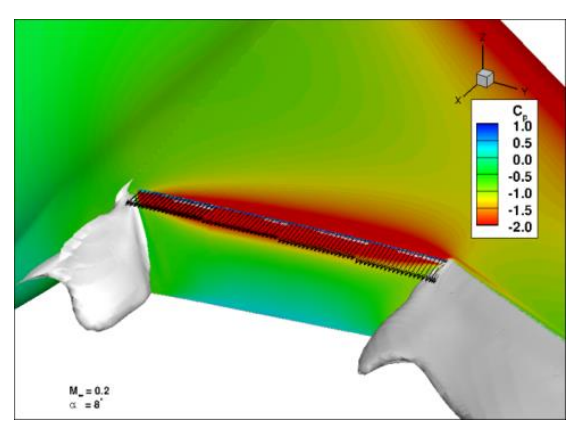

Wide jet

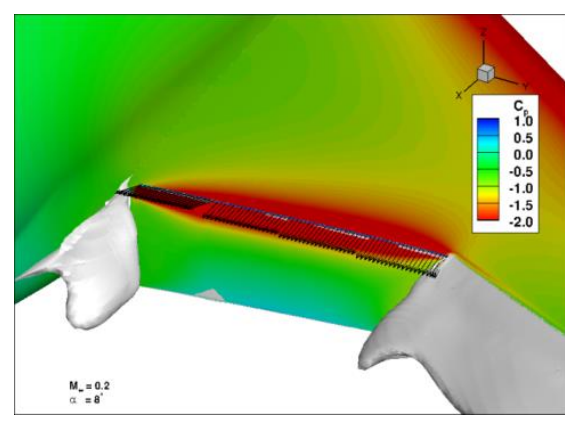

Blowing towards fuselage

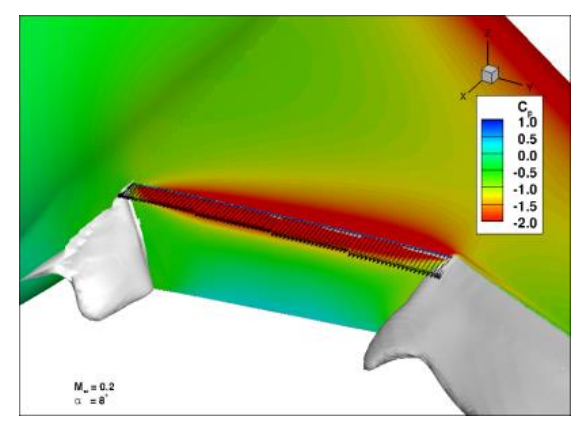

Close to fuselage jet

Figure 14. Optional side-of-fuselage treatment of flow control. 


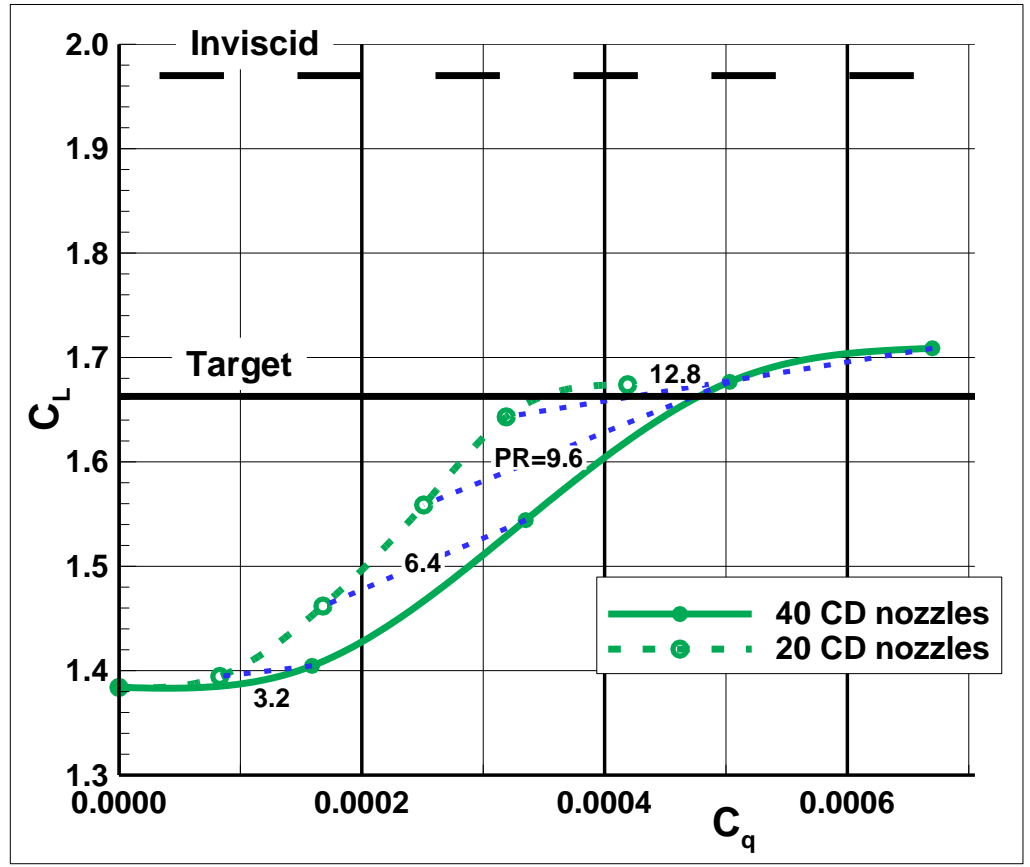

PR 6.4

All actuators on

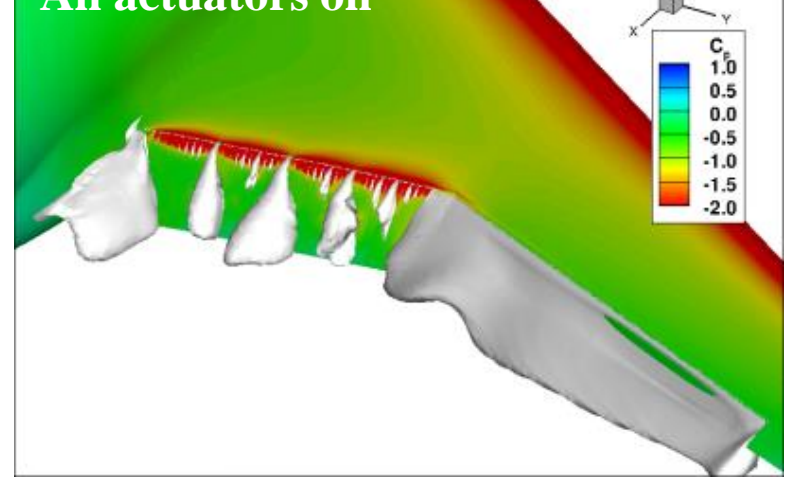

(a) Lift vs mass flow

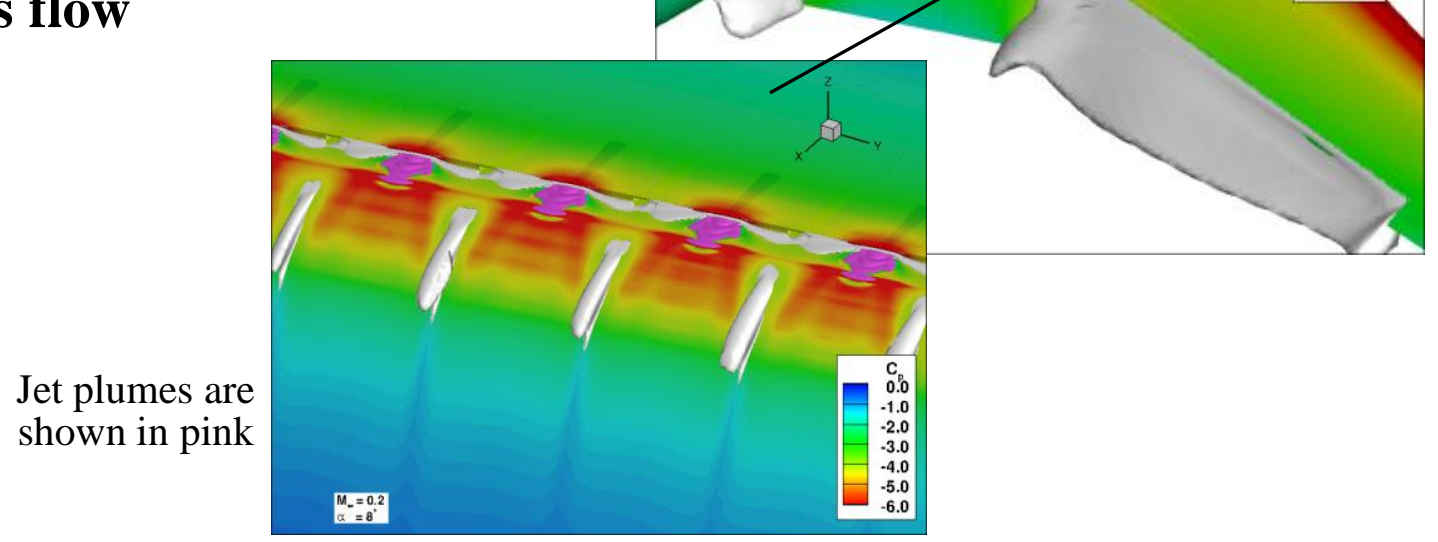

(b) Flow fields at the same $C_{q}$

Figure 15. Actuation patterns for the system of convergent-divergent nozzles. 


\section{Constant area section}

Long divergent section

\section{Straight upper wall}

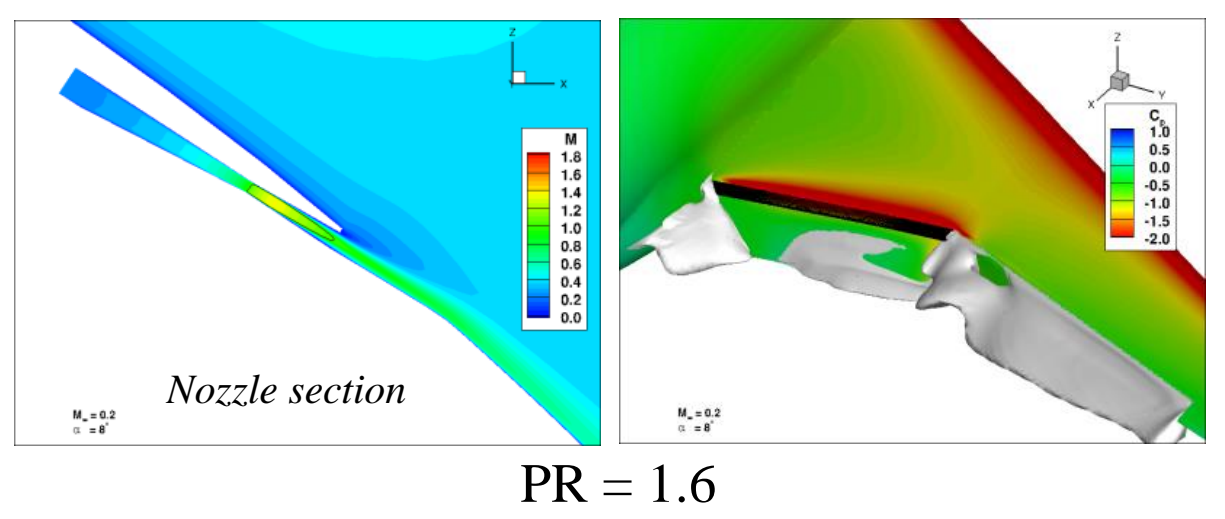

(a) Nozzle section

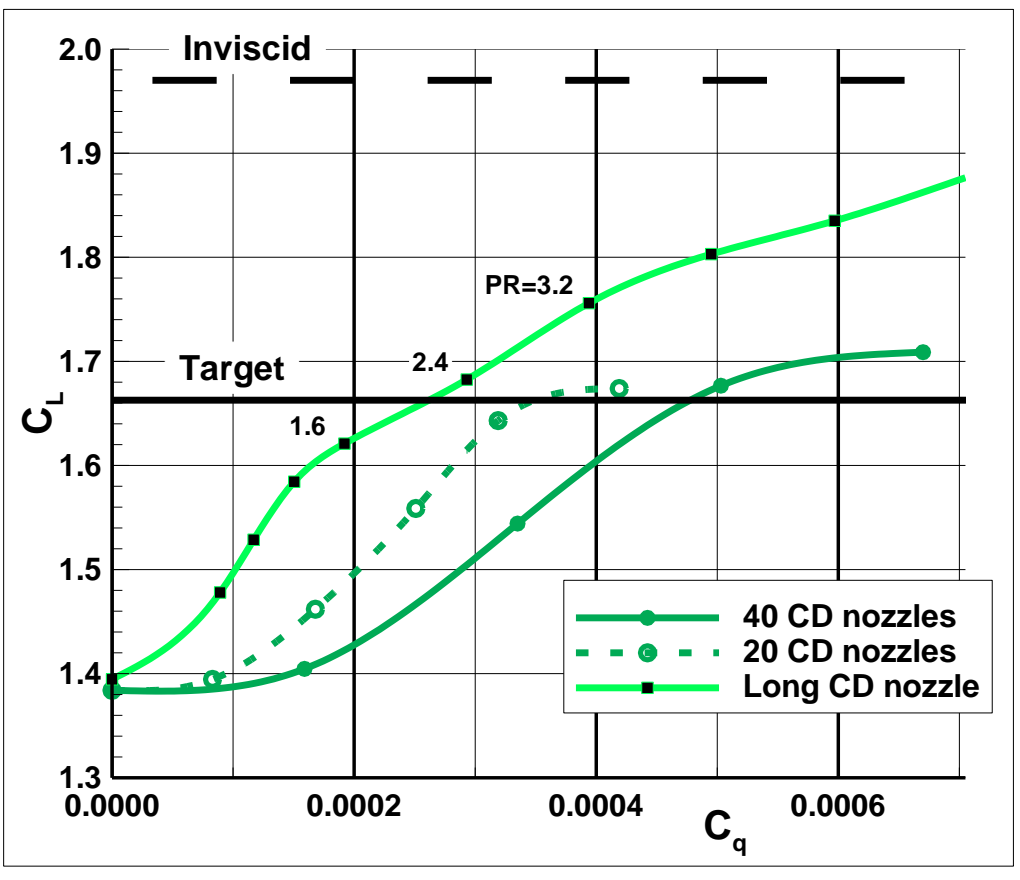

(b) Lift vs mass flow
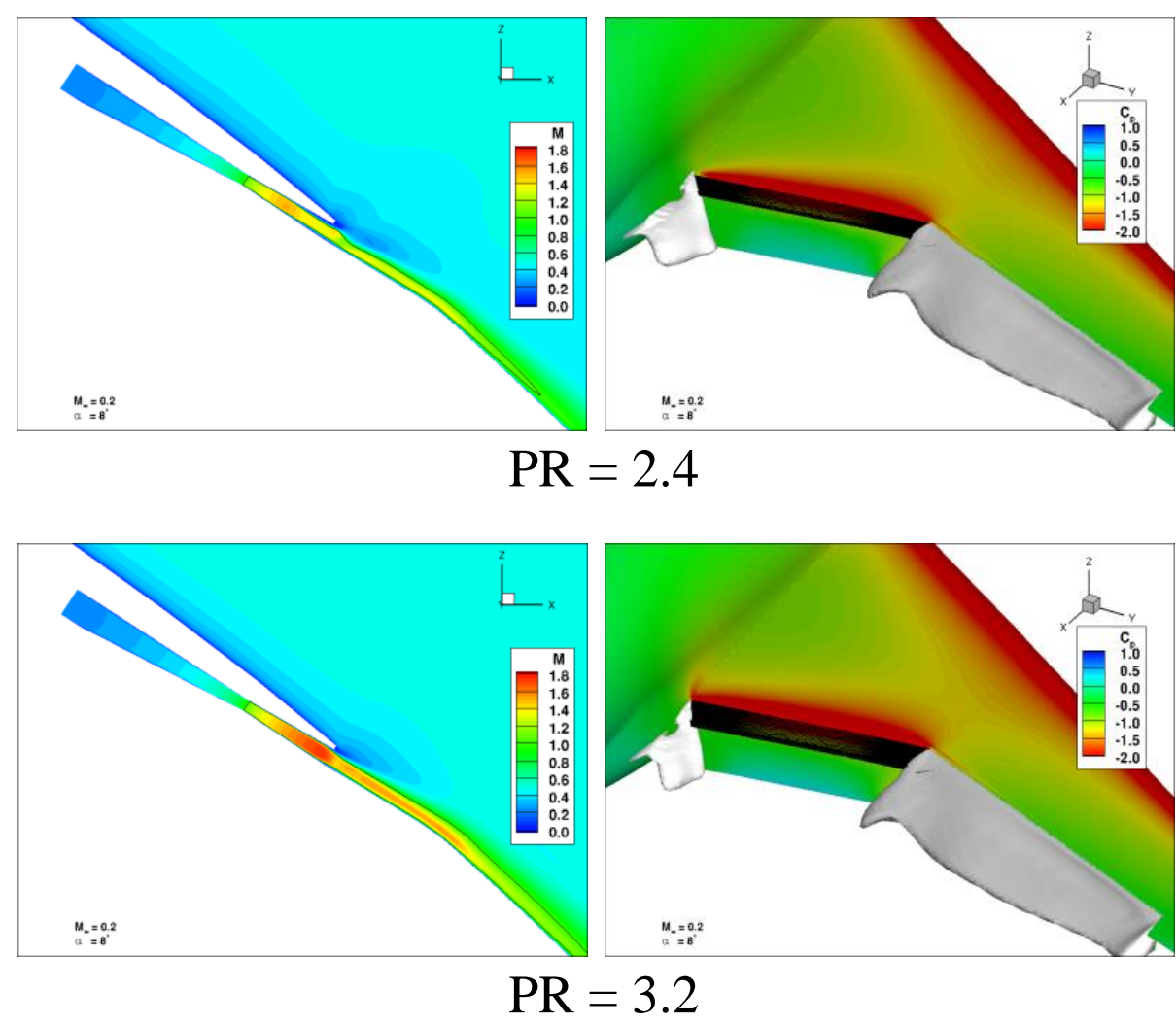

(c) Flow fields

Figure 16. System of spanwise convergent-divergent nozzle. 

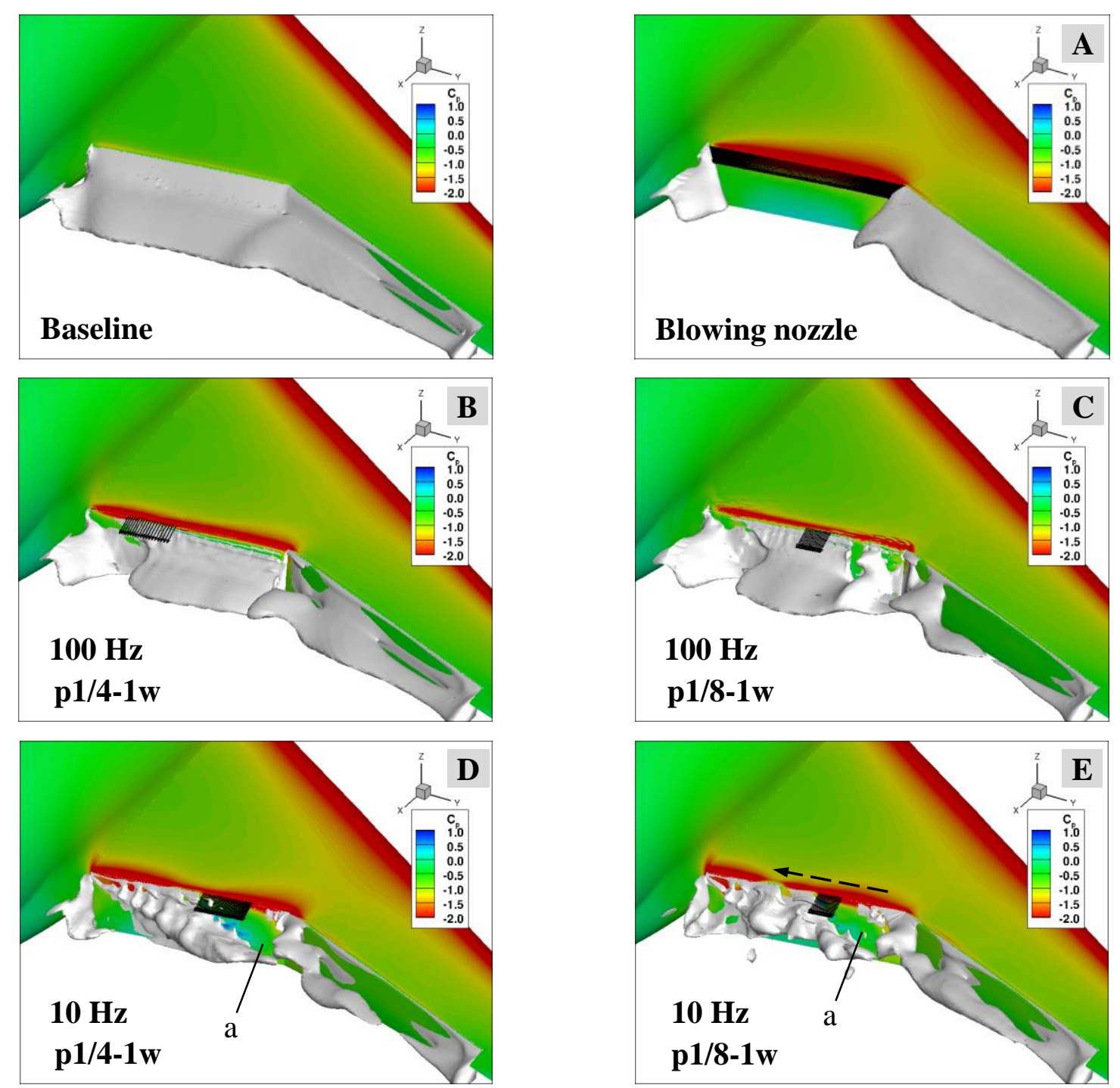

Figure 17. Instantaneous flow fields due to the traverse actuation. 


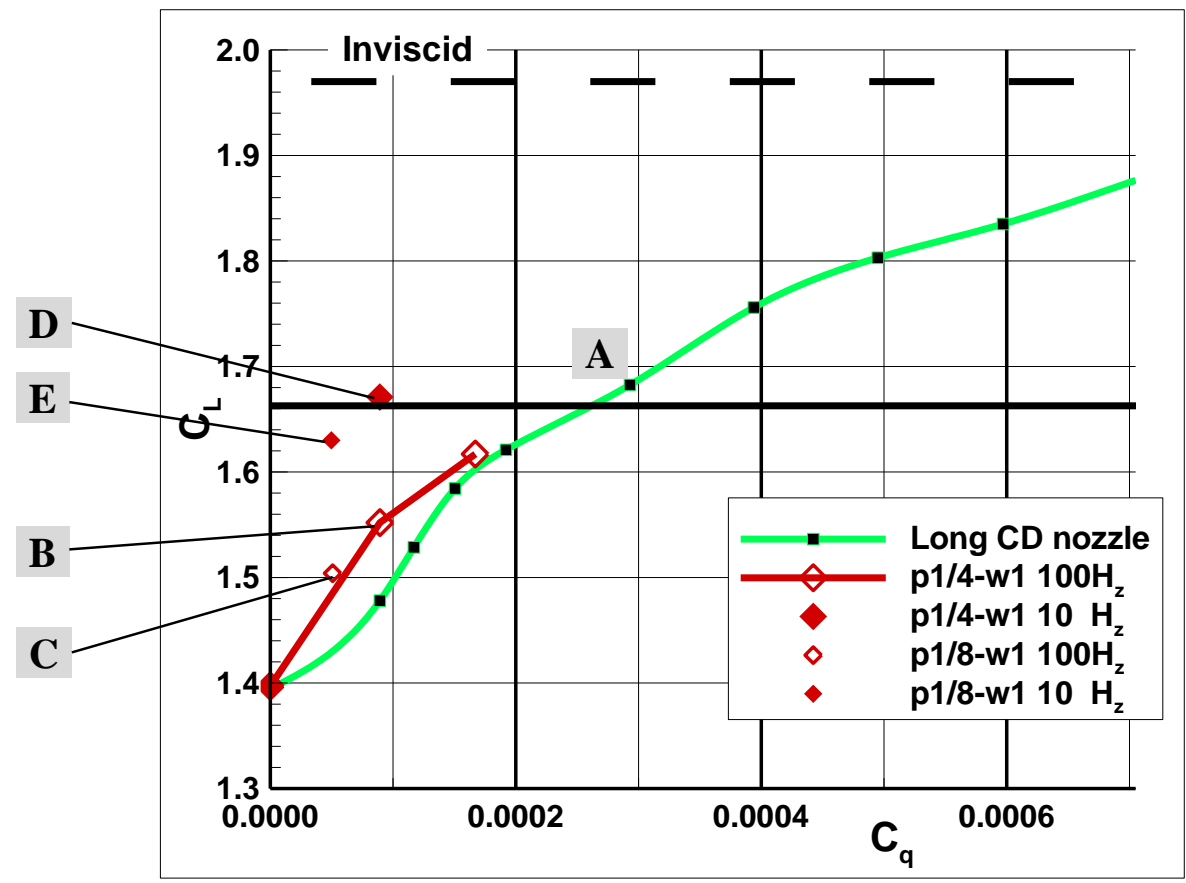

Figure 18. Lift versus mass flow for the traverse actuation. 